\title{
Capital Controls with International Reserve Accumulation: Can this Be Optimal? ${ }^{1}$
}

\author{
Philippe Bacchetta \\ Kenza Benhima \\ University of Lausanne \\ University of Lausanne \\ CEPR \\ Yannick Kalantzis \\ Banque de France
}

January 13, 2012

\footnotetext{
${ }^{1}$ We would like to thank Gong Cheng for excellent research assistance. The paper has benefited from discussions with Régis Barnichon, Gianluca Benigno, Alessandro Rebucci, and Pedro Teles and from comments by participants of the conference 'The Financial Crisis: Lessons for International Macroeconomics,' in Paris and seminar participants at LSE. Bacchetta and Benhima gratefully acknowledge financial support from the National Centre of Competence in Research "Financial Valuation and Risk Management" (NCCR FINRISK). Bacchetta also acknowledges support from the ERC Advanced Grant \#269573, and the Swiss Finance Institute.
} 


\begin{abstract}
Motivated by the Chinese experience, we analyze a semi-open economy where the central bank has access to international capital markets, but the private sector has not. This enables the central bank to choose an interest rate different from the international rate. We examine the optimal policy of the central bank by modelling it as a Ramsey planner who can choose the level of domestic public debt and of international reserves. The central bank can improve savings opportunities of credit-constrained consumers modelled as in Woodford (1990). We find that in a steady state it is optimal for the central bank to replicate the open economy, i.e., to issue debt financed by the accumulation of reserves so that the domestic interest rate equals the foreign rate. When the economy is in transition, however, a rapidly growing economy has a higher welfare without capital mobility and the optimal interest rate differs from the international rate. We argue that the domestic interest rate should be temporarily above the international rate. We also find that capital controls can still help reach the first best when the planner has more fiscal instruments. Keywords: Reserve Accumulation; Capital Controls; Ramsey Planner; Credit Constraints.
\end{abstract}

JEL Classification Numbers: E58; F36; F41. 


\section{Introduction}

China has been a key contributor to global imbalances with both a significant current account surplus and a substantial accumulation of international reserves by the central bank. Figure 1 shows the increase in both variables in recent years. The parallel evolution of these two variables illustrates an interesting feature of the Chinese economy. On the one hand, there are strict restrictions on private capital flows, which characterize a closed economy. On the other hand, there are substantial net capital outflows, through the accumulation of international reserves. This hybrid system differs from the usual open economy or closed economy paradigms and has receive little attention in the literature. However, to analyze the macroeconomic behavior of the Chinese economy, it seems fundamental to have a good understanding of this specific structure.

The objective of this paper is to analyze an economy where the central bank has access to international capital markets, but the private sector has not. We call this situation a semi-open economy. ${ }^{1}$ We want to address two main questions in this context. First, what is the optimal policy of the central bank? For this purpose, we model the central bank as a Ramsey planner in a closed economy who has access to the international capital market and we examine optimal policies. The second question is how does the semiopen economy compare to an open economy? This question is interesting because we know that an open economy typically produces a higher welfare than a closed economy, in particular because it allows intertemporal trade. But the semi-open economy also enables intertemporal trade. Moreover, the semi-open economy allows to choose the real interest rate, contrarily to the open economy. Thus, an economy with limited capital mobility may have a higher welfare than an open economy.

In a model where households face a borrowing constraint, we find that the decentralized equilibrium of an open economy may not be socially optimal and a combination of capital controls and reserve policy may improve welfare. If the planner is not subject to the same borrowing constraint, it can improve the households' intertemporal allocation

\footnotetext{
${ }^{1}$ Jeanne (2011) also analyzes a semi-open economy, but in a context that gives no role for optimal policies.
} 
of resources. When the set of policy instruments is limited, the best way to improve intertemporal allocation is to manipulate the interest rate, which is equivalent to subsidizing borrowing or saving. But allowing the domestic interest rate to deviate from the world interest rate requires capital controls. And when capital controls are in place, intertemporal trade for the aggregate economy can only be achieved by variations in the level of reserves.

We consider a simple economy with precautionary saving emanating from creditconstrained consumers. The model is an extension of the endowment economy presented by Woodford (1990). There are two groups of consumers with endowments fluctuating periodically. In each period, one of the groups has a low endowment and may not be able to smooth consumption due to a credit constraint. This may generate precautionary saving in the period of high endowment. In an open economy this model would imply excess saving based on several mechanisms proposed in the recent literature on global imbalances. First, there is precautionary saving as in Mendoza et al. (2009) ${ }^{2}$ associated with a demand for liquidity in high revenue periods as in Bacchetta and Benhima (2010). Second, when credit constraints are tight, there is a lack of domestic assets in the spirit of Caballero et al. (2008). In a semi-open economy, the central bank may improve the saving opportunities by providing liquid assets. This can be associated with an increase in international reserves. In practice, the liquidity provided by a central bank is typically made of commercial banks reserves and of central bank bonds. Figure 2 shows that in the Chinese economy there is a close relationship between central bank liquidity and international reserves.

In the steady state of this economy, however, there is no need to improve the intertemporal allocation if we assume that the discount rate and the growth rate are the same as in the rest of the world. The reason is that consumers are able to avoid the constraint when they approach the steady state. Consequently, it is optimal to replicate the open economy in the steady state, and thus to set the domestic interest rate equal to the international rate. The optimal amount of international reserves in a semi-open

\footnotetext{
${ }^{2}$ Although there is no uncertainty in the Woodford (1990) model, the heterogeneity across consumers allows to capture a mechanism similar to a more complex Bewley-Ayiagari model.
} 
economy is then equal to the amount of foreign assets that would prevail in an open economy. Basically, the central bank provides liquidity and finances it by the accumulation of international reserves. Therefore, as suggested by Song et al. (2010) or Wen (2011), the central bank may simply serve as intermediary between the private sector and international capital markets when the economy has limited capital mobility.

Results are different when we consider growing economies that converge to their steady state. This situation is more relevant in the context of the Chinese economy. In this case, the open economy is usually not the first best, so that the optimal interest rate differs from the international interest rate. The reason is that credit constraints are binding on the convergence path as consumers are not able to smooth their consumption. Thus, there is an incentive for the planner to relax the credit constraint. However, whether the domestic interest rate should be higher or lower than the international interest rate is ambiguous. This is due to the heterogeneity of households and the fact that there are both lenders and borrowers. On the one hand, there is an incentive to lower the interest rate for low-endowment consumers who borrow. On the other hand, there is an incentive to increase the interest rate for high-endowment consumers who save because they will be constrained in the subsequent period. Furthermore, the optimal interest rate is affected by the dynamic evolution of the credit constraint tightness. For example, there is an incentive to temporarily decrease the interest rate when the constraint is temporarily stronger. Overall, we find that it is optimal to temporarily increase the interest rate in an economy with characteristics similar to the Chinese economy, namely: i) tight credit constraints; ii) a strong demand for precautionary saving; iii) sustained growth.

We focus on a planner, the central bank, who has only two instruments: the levels of domestic public debt and of international reserves. When more instruments are available, like lump-sum taxes or consumption taxes, we show that the planner can reach a first best by fully relaxing the credit constraint. ${ }^{3}$ In these cases, however, precautionary saving by the private sector disappears and there is no role for reserve accumulation. Nevertheless, we still find that limited capital mobility gives a higher welfare, and allows to reach the

\footnotetext{
${ }^{3}$ Benigno et al. (2011) also find that the credit constraint stops binding when the planner has a tax on traded or on non-traded goods consumption.
} 
first best, when the planner can choose consumption taxes. The reason is that modifying the domestic interest rate can offset the distortionary impact of consumption taxes on households intertemporal decisions.

Our analysis shares various features with existing literature. In particular, the optimal provision of liquidity in the presence of precautionary saving due to borrowing constraints is a standard result (e.g., see Woodford, 1990, or Aiyagari and McGrattan, 1998). Moreover, the desirability of using the international capital market to provide domestic liquidity when taxes are distortionary can be found in Holmstrom and Tirole (2002, 2011).

On the other hand, our perspective differs from the vast literature on international reserves and on capital flows. Much of the literature on international reserves focuses on its role as an insurance against aggregate shocks. ${ }^{4}$ In contrast, the accumulation of reserves in our paper arises from the insurance of idiosyncratic shocks. ${ }^{5}$ Consequently, the perspective taken in this paper should be seen as complementary to the literature. Actually, Jeanne and Rancière (2011) find that the precautionary motive against aggregate shocks is not sufficient to explain international reserve accumulation in China.

Our analysis also differs from the recent literature on the optimality of capital controls or more generally on limits to borrowing (e.g., Korinek, 2010, Jeanne and Korinek, 2011, Bianchi, 2011, Bianchi and Mendoza, 2010, or Benigno et al., 2010). In that literature, the justification for limits to capital mobility comes from pecuniary externalities. Typically, external borrowing affects a relative price, the exchange rate or an asset price, so that the financial constraint becomes tighter. The private sector does not internalize the effect, which gives a role for government intervention. In our case, however, the justification comes simply from the presence of credit constraints in a growing economy. Consumers

\footnotetext{
${ }^{4}$ For recent contributions see, for example, Aizenman (2011), Aizenman and Lee (2007), Barnichon (2009), Durdu et al. (2009), or Obstfeld et al. (2011).

${ }^{5} \mathrm{~A}$ similar difference is found in the literature on optimal government debt in contexts where Ricardian equivalence does not hold. When shocks are at the aggregate level, it is optimal for a government to accumulate assets (e.g., see Aiyagari et al., 2002). In contrast, when there are idiosyncratic shocks in the private sector, it is optimal for the government to issue debt. Shin (2006) introduces both motives in a closed economy. It would be interesting to extend such an analysis to a semi-open economy. In general, we can conjecture that there would be motives for holding international reserves coming both from aggregate and from idiosyncratic shocks.
} 
would be better off in reallocating resources from the future to the present and government intervention can increase welfare by using its available instruments.

The rest of the paper is organized as follows. In Section 2, we describe the model and the various equilibrium concepts. In Section 3, we analyze the decentralized closed economy and examine the impact of changing the supply of government bonds. In Section 4, we examine the Ramsey planner problem with foreign reserves. In Section 5 we examine the case where the planner can also choose optimally the consumption tax rate. Section 6 concludes.

\section{Model}

The economy is inhabited by infinitely-lived households who consume every period, but alternate between low and high endowment periods as in Woodford (1990, section I). This structure implies that households save in their periods of high endowment and would like to borrow in their periods with low endowment. ${ }^{6}$ But the extent of borrowing can be limited by creditors, which leads to a desire for additional precautionary saving. Saving is in the form of bonds that we will call liquid assets. There is a gross interest rate $r_{t}$ on lending and borrowing.

In addition to households there is a Ramsey planner, that we call a central bank, who can issue liquid assets and hold international reserves. When credit constraints are tight, the demand for funds by cash-poor households is small. In a closed economy, this limits the opportunities to save for cash-rich households. In this case the provision of liquid assets by the central bank may be desirable.

\section{$2.1 \quad$ Households}

There are two groups of mass one of households. At time $t$, a first group of households receives an endowment $Y_{t}$, while the second group receives $a Y_{t}$, with $0 \leq a<1$. At $t+1$, the first group receives $a Y_{t+1}$ while the second receives $Y_{t+1}$, and so on. We refer to the

\footnotetext{
${ }^{6}$ There are three basic differences with Woodford (1990): i) consumers may be able to borrow; ii) there is a Ramsey planner; iii) there is no capital stock.
} 
group with $Y$ as cash-rich households, or depositors, and the group with $a Y$ as cash-poor households, or borrowers. Each household alternates between a cash-rich and a cash-poor state, and each period there is an equally-sized population of rich and poor.

Households maximize:

$$
\sum_{s=0}^{\infty} \beta^{s} u\left(c_{s}\right)
$$

We denote consumption during the cash-rich period as $c^{D}$. In this period, households will typically hold deposits $D$. These deposits are one-period contracts, either as direct loans to borrowing cash-poor households or in public debt holdings. ${ }^{7}$ Consumption during the cash-poor period is denoted $c^{L}$. In this period, households borrow $L$. Consider a household that is cash-rich at time $t$ and cash-poor at date $t+1$. His budget constraints at $t$ and $t+1$ are:

$$
\begin{gathered}
Y_{t}-r_{t} L_{t}=\tau_{t} c_{t}^{D}+D_{t+1} \\
a Y_{t+1}+r_{t+1} D_{t+1}=\tau_{t+1} c_{t+1}^{L}-L_{t+2}
\end{gathered}
$$

The income of the household at date $t$, which is composed of endowment $Y_{t}$ minus debt repayments $r_{t} L_{t}$, is allocated to deposits $D_{t+1}$ and consumption $c_{t}^{D}$, including a flatrate consumption tax $\tau_{t}-1$ with $\tau_{t}>0$. In the following period, at $t+1$, his income is composed of the return on deposits, $r_{t+1} D_{t+1}$, and of $a Y_{t+1}$. This has to pay for consumption $c_{t+1}^{L}$ and taxes. Typically the cash-poor household will borrow, so that at the optimum $L_{t+2} \geq 0$.

The cash-poor household might face a credit constraint when borrowing at date $t+1$. Due to standard moral hazard arguments, a fraction $0 \leq \phi<1$ of the endowment is used as collateral for bond repayments:

$$
r_{t+2} L_{t+2} \leq \phi Y_{t+2}
$$

The multiplier associated with this constraint is denoted $u^{\prime}\left(c_{t+2}^{D}\right) \lambda_{t+2}$.

\footnotetext{
${ }^{7}$ Alternatively, we could introduce a banking sector that allocates deposits between loans and public debt.
} 
Cash-rich households at time $t$ satisfy the following Euler equation:

$$
u^{\prime}\left(c_{t}^{D}\right)=\beta r_{t+1} \frac{\tau_{t}}{\tau_{t+1}} u^{\prime}\left(c_{t+1}^{L}\right)
$$

Similarly, poor households at date $t$ satisfy the following Euler equation:

$$
u^{\prime}\left(c_{t}^{L}\right)=\beta r_{t+1} \frac{\tau_{t}}{\tau_{t+1}} u^{\prime}\left(c_{t+1}^{D}\right)\left(1+\lambda_{t+1}\right)
$$

The intertemporal choice of a cash-poor household is distorted when the credit constraint is binding, because $\lambda_{t+1}>0$. The following slackness condition has also to be satisfied:

$$
\left(\phi Y_{t+1}-r_{t+1} L_{t+1}\right) \lambda_{t+1}=0
$$

\subsection{Central Bank Policy}

The central bank issues domestic liquidity $B_{t+1}$ that pays an interest rate $r_{t+1}$ and has access to foreign reserves $B_{t+1}^{*}$ that yield the world interest rate $r^{*}$. We assume that the world interest rate is $r^{*}=1 / \beta$. Private agents cannot buy external bonds directly, so the domestic interest rate is determined in the domestic bond market. Equilibrium in this market is:

$$
B_{t+1}=D_{t+1}-L_{t+1}
$$

In the presence of capital controls, only the central bank has access to external liquidity, so it has a monopoly over the supply of liquidity to domestic agents. It can therefore manipulate the domestic interest rate $r_{t}$ by appropriately setting the supply of liquidity $B$. The possibility of accumulating reserves $B^{*}$ enables the central bank to change the domestic liquidity by simply expanding its balance sheet. The central bank can then match the desired domestic liquidity by accumulating reserves. ${ }^{8}$

When the central bank policy creates a wedge between $r_{t}$ and $r^{*}$, this generates

\footnotetext{
${ }^{8}$ Notice that this institutional framework is well illustrated by Figure 2, where the sum of the central bank bonds and reserve deposits of commercial banks $(B)$ closely matches the difference between deposits and credits of commercial banks $(D-L)$ and moves together with international reserves $\left(B^{*}\right)$.
} 
revenues or losses that have to be financed. In practice, central banks transfer their revenues and losses to the government. Therefore, there is a fiscal side to central bank policy. We assume that the changes in central bank revenues affect the consumption tax $\tau_{t}-1$. Absent government consumption, the aggregate budget constraint of the central bank and the government is then:

$$
r^{*} B_{t}^{*}+B_{t+1}+\left(\tau_{t}-1\right)\left(c_{t}^{D}+c_{t}^{L}\right)=B_{t+1}^{*}+r_{t} B_{t}
$$

In the following, we will consider two cases. First, for the sake of realism, Section 4 assumes that the central bank cannot change the tax rate $\tau_{t}-1$ which is then constant. This is justified by the fact that, in practice, monetary policy is more flexible than fiscal policy. The sequence of budget constraints (9), together with the usual no-ponzi condition, implies that the constant level of the tax rate is then simply set to balance the net present value of revenues and losses by the central bank:

$$
(\tau-1) \sum_{t \geq 0} \frac{c_{t}^{D}+c_{t}^{L}}{\left(r^{*}\right)^{t}}+r^{*}\left(B_{0}^{*}-B_{0}\right)=\sum_{t \geq 0} \frac{\left(r_{t}-r^{*}\right) B_{t}}{\left(r^{*}\right)^{t}}
$$

Then, Section 5 examines the case where $\tau_{t}$ is an additional instrument for the Ramsey planner which can be freely chosen every period. In practice, this would mean that fiscal policy is highly flexible and that the central bank can coordinate with the fiscal authority to maximize welfare. In this second case, the planner can supply liquidity without accumulating reserves if it chooses to finance the bonds $B$ with the consumption tax.

Notice that the wedge between $r$ and $r^{*}$ is akin to a subvention (tax) on deposits (loans). ${ }^{9}$ Setting a higher domestic interest rate is therefore equivalent to subsidizing deposits and taxing loans, while setting a lower interest rate is equivalent to taxing deposits and subsidizing loans. When setting the domestic interest rate, the central bank faces a trade-off between depositors and borrowers.

\footnotetext{
${ }^{9}$ Indeed, the net asset returns $r^{*} B^{*}-r B$ of the central bank can be rewritten as $r^{*}\left(B^{*}-B\right)-(r-$ $\left.r^{*}\right) B=r^{*}\left(B^{*}-B\right)-\left(r-r^{*}\right) D+\left(r-r^{*}\right) L$, which is the net return on central bank assets at the world interest rate, minus subsidies on deposits, plus taxes on loans, if $r>r^{*}$.
} 
When the central bank sets $r=r^{*}$ it can replicate the open economy. In general, we consider three policy regimes, which correspond to different constraints imposed on the set of policy instruments:

Definition 1 (Policy regimes) We define the following policy regimes:

- The closed economy, where $B^{*}=0$ and $r \in \Re^{+}$;

- The open economy, where $B^{*} \in \Re$ and $r=r^{*}$;

- The semi-open economy, where $B^{*} \in \Re$ and $r \in \Re^{+}$

In the semi-open economy regime, the central bank uses its exclusive access to foreign bonds to set the domestic supply of liquidity and manipulate the domestic interest rate as it wishes. Since this is the more general case, we will consider optimal policy within the semi-open economy regime. Indeed, both the open economy and the closed economy are nested in the semi-open economy. In the closed economy, the central bank's access to reserve accumulation is restricted, so neither the central bank nor the private agents can trade foreign bonds. In the open economy regime, we assume that the central bank provides the desired supply $B_{t}$ at interest rate $r^{*}$ to the private sector. This is equivalent to let the private sector buy directly foreign assets as $B_{t}$ and $B_{t}^{*}$ are perfect substitutes in this case. In this regime, the optimal interest rate is equal to the world interest rate $r^{*}$ and capital controls are unnecessary. But when the optimal $r$ differs from $r^{*}$, capital controls are welfare-improving.

As a Ramsey planner, the central bank will choose a decentralized equilibrium to maximize its social objective:

$$
\sum_{s=0}^{\infty} \beta^{s}\left[u\left(c_{s}^{D}\right)+u\left(c_{s}^{L}\right)\right]
$$

In the next section, we describe the decentralized equilibrium and in Section 4 we analyze optimal policies. 


\section{Decentralized equilibrium}

In this section, we examine the properties of a decentralized equilibrium for a given policy. First, we describe how the credit constraint affects consumption behavior and leads to additional saving. Then, we analyze the steady state and determine the conditions under which the economy is constrained. At the end of the section, as a benchmark case, we analyze a growing open economy without any policy intervention. In order to get analytical results, this section considers the case of a logarithmic utility function $u\left(c_{t}\right)=\log \left(c_{t}\right)$.

We define a decentralized equilibrium as follows:

Definition 2 (Decentralized equilibrium) Given initial conditions $r_{0} L_{0}, r_{0} D_{0}$, and $B_{0}^{*}$, a decentralized equilibrium under a given policy regime is a sequence of prices $\left\{r_{t}\right\}_{t \geq 0}$, allocations $\left\{D_{t+1}, L_{t+1}, c_{t}^{D}, c_{t}^{L}\right\}_{t \geq 0}$ and central bank policy $\left\{B_{t+1}, B_{t+1}^{*}, \tau_{t}\right\}_{t \geq 0}$ such that: (i) given the price system and the central bank policy, the allocation solves the households' problems (equations (2)-(7) are satisfied); (ii) given the allocation and the price system, the central bank policy satisfies the sequence of central bank budget constraints (9) and a given policy regime; (iii) equilibrium in the domestic bond market (8) is satisfied; (iv) $B_{t}^{*}>-A$ for some large positive $A$.

The last condition rules out ponzi schemes by the central bank. As explained in Section 2 , the sequence of taxes $\tau_{t}$ can be constant or variable across time depending on whether the central bank has access to the fiscal instrument.

\subsection{Precautionary Saving}

In the absence of credit constraints and with log-utility, households would consume a fixed fraction of their intertemporal wealth:

$$
\begin{aligned}
c_{t}^{D *} & =\frac{1-\beta}{\tau_{t}}\left(\sum_{k=0}^{\infty} \frac{Y_{t+2 k}}{\prod_{i=1}^{2 k} r_{t+i}}+\sum_{k=0}^{\infty} \frac{a Y_{t+2 k+1}}{\prod_{i=1}^{2 k+1} r_{t+i}}-r_{t} L_{t}\right), \\
c_{t}^{L *} & =\frac{1-\beta}{\tau_{t}}\left(\sum_{k=0}^{\infty} \frac{a Y_{t+2 k}}{\prod_{i=1}^{2 k} r_{t+i}}+\sum_{k=0}^{\infty} \frac{Y_{t+2 k+1}}{\prod_{i=1}^{2 k+1} r_{t+i}}+r_{t} D_{t}\right) .
\end{aligned}
$$


Then, the unconstrained (or notional) demands for deposits and loans $D_{t+1}^{*}$ and $L_{t+1}^{*}$ are given by replacing $c_{t}^{D *}$ and $c_{t}^{L *}$ in the budget constraints (2) and (3).

To understand what happens when cash-rich households are constrained in $t+1$, we use the Euler equation to substitute for consumptions in the budget constraints and derive the demand for deposits:

$$
D_{t+1}=\frac{1}{1+\beta}\left(\beta\left(Y_{t}-r_{t} L_{t}\right)-\frac{a Y_{t+1}}{r_{t+1}}-\frac{L_{t+2}}{r_{t+1}}\right)
$$

Since deposits are used to smooth consumption between the cash-rich period and the cash-poor period, they depend negatively on future borrowings $L_{t+2}$. As the credit constraint imposes that $L_{t+2} \leq L_{t+2}^{*}$, we have then $D_{t+1} \geq D_{t+1}^{*}$. This means that when households anticipate that their borrowing capacity will be limited in the future, they save more. More specifically, the level of loans contracted by cash-poor households that are constrained in $t$ is given by:

$$
L_{t+1}=\frac{\phi Y_{t+1}}{r_{t+1}}
$$

The interest rate $r_{t+1}$ that clears the market for domestic liquidity must be such that total deposits $D_{t+1}$ equal outside liquidity $B_{t+1}$ and inside liquidity $L_{t+1}$, as stated by equation (8), for a given level of $B_{t+1}$.

\subsection{Liquidity Supply in the Steady State}

Whether the economy is constrained or not depends on the adequation of supply and demand for liquidity. An economy with a tight constraint needs a larger supply of liquidity $B$. This can be analyzed precisely in the deterministic steady state (since there is no uncertainty). For a given constant level of $Y$, a steady state is a decentralized equilibrium with constant liquidity provision $B$, reserve holdings $B^{*}$ and taxes $\tau$ satisfying the central bank budget constraint (9).

The following proposition characterizes the steady states of the model depending on the amount of liquidity $B$. For the sake of simplicity, the analysis is restricted to symmetric equilibria where both types of households have the same (possibly state-dependent) 
level of consumptions and wealths. ${ }^{10}$

Proposition 1 If $\frac{B}{Y}<\beta\left(\frac{1-a}{1+\beta}-2 \phi\right)$, there is a unique steady state with a binding credit constraint where the interest rate $r<1 / \beta$ increases with $\frac{B}{Y}$. The ratio of relative consumption depends on $r$ : $\frac{c^{L}}{c^{D}}=\beta r<1$.

If $\frac{B}{Y} \geq \beta\left(\frac{1-a}{1+\beta}-2 \phi\right)$, the credit constraint does not bind and symmetric steady states are characterized by $\beta r=1$.

Proof. See Appendix A.

Proposition 1 implies that a binding credit constraint leads to a lower interest rate. This is the case when $\phi$ is low and $B / Y$ is small. When the constraint binds, cash-poor households are not able to supply enough liquid assets to cash-rich households because of their limited collateral. As a result, liquidity is overpriced compared to the first best, which corresponds to a depressed interest rate. It also prevents cash-poor households from transferring some of their consumption from the next to the current period, so that consumption is lower in the L-state than in the D-state.

The provision of liquidity by the central bank affects the decentralized equilibrium in the following way. A larger amount of bonds $B$ provides more saving instruments to cash-rich households, alleviating the limited supply of bonds by cash-poor households and decreasing the price of liquidity. As shown in Proposition 1, this results in a higher interest rate. As the steady-state supply of public bonds increases, the interest rate increases until it reaches $r=1 / \beta$. At that point, the constraint stops binding and the supply of public bonds has no more effect on the interest rate and the allocation of resources.

Based on the Proposition, we define liquidity-scarce and liquidity-abundant countries as follows:

Definition 3 A liquidity-scarce country is one where $\phi<\frac{1-a}{2(1+\beta)}$. A liquidity-abundant country is one where $\phi \geq \frac{1-a}{2(1+\beta)}$.

\footnotetext{
${ }^{10}$ Equilibria where the borrowing constraint binds for both groups of households when cash-poor are always symmetric as wealth is pinned down by the borrowing constraint. However, when the constraint does not bind for at least one group of households when cash-poor, there is a continuum of equilibria corresponding to different levels of wealth.
} 
In a liquidity-scarce country, agents need a positive supply of bonds by the central bank to achieve a first-best steady state, because private agents supply insufficient liquidity. In contrast, in a liquidity-abundant country there is no need for public supply of liquidity since private agents issue more bonds.

Corollary 1 (Closed economy) Consider a closed economy with no taxes $(\tau=1)$ and therefore $B=0$. If the economy is liquidity-abundant, the credit constraint does not bind in the steady state and $\beta r=1$. If it is liquidity-scarce, the constraint binds in the steady state and $c^{L} / c^{D}=\beta r<1$.

Corollary 2 (Open economy) Consider an open economy with $\beta r^{*}=1$ and no taxes $(\tau=1)$. The constraint does not bind in the steady state and $\frac{B^{*}}{Y}=\frac{B}{Y} \geq \beta\left(\frac{1-a}{1+\beta}-2 \phi\right)$. If the economy is liquidity-scarce, then $\frac{B^{*}}{Y} \geq 0$.

Corollary 1 shows that, if the country is liquidity-scarce and in the absence of taxation, there is an insufficient domestic supply of liquidity in the closed economy, so households are credit constrained in the long run. In contrast, Corollary 2 shows that reserve accumulation by the central bank in the open economy allows to eliminate the credit constraints.

That $B^{*}>0$ makes the borrowing constraint unbinding in liquidity-scarce countries, which is socially optimal as we will see, depends in particular on the absence of taxes. As suggested by Holmstrom and Tirole $(2002,2011)$, when taxes are distortionary, the international capital market is the best source for domestic liquidity. Thus, it is optimal for the central bank to simply serve as intermediary between the private sector and the international capital market. Equivalently, it would be optimal to liberalize private capital flows when the economy is in the steady state with $\beta r^{*}=1$.

While the steady state provides tractable solutions and interesting insights, it seems more relevant to analyze growing economies. In this case, even the open economy might face binding borrowing constraints on the convergence path before reaching the steady state. We examine the optimal policy in the next section, but as a benchmark it is useful to examine the dynamics of the open economy. 


\subsection{The Convergence of Open Economies}

Consider a growing open economy without planner's intervention, that is $\tau=1$ and $r=r^{*}=1 / \beta$. The endowment is growing at rate $g_{t}$, i.e., $Y_{t+1}=\left(1+g_{t+1}\right) Y_{t}$. We consider an economy where $g_{t}$ is driven by the following process:

$$
g_{t+1}=\mu g_{t}
$$

where $0 \leq \mu<1$. This is for example the case of an economy that catches up toward the world's productivity frontier. We examine in particular whether the economy is constrained on the convergence path and whether it is asymptotically constrained or unconstrained.

In the open economy case, each household faces the world interest rate, so it behaves independently from the others. It is therefore sufficient to examine the behavior of a given household. The open economy is then only the aggregation over the two groups of households.

Proposition 2 Consider an open economy with $\beta r^{*}=1$ and no taxes $(\tau=1)$. If cashpoor households are constrained in $t$ and $g_{t}$ is small, then they are constrained in all their subsequent cash-poor periods and unconstrained in all their subsequent cash-rich periods. Moreover, $\lambda_{t+2 k+1} \simeq \mu^{2 k}(1+\mu) \frac{1-\phi+\mu \beta a+\mu^{2} \beta^{2} \phi}{1-\phi+\beta a+\beta^{2} \phi} g_{t}, k \geq 0$.

Proof. See the Appendix.

The Proposition gives conditions for the credit constraints to stay binding, as well as an approximation for $\lambda$. Notice that when $\mu$ goes to one, which corresponds to permanent growth, the value of $\lambda$ goes to $2 g$. More importantly, the economy stays constrained on the convergence path but is asymptotically unconstrained $\left(\lim _{t \rightarrow \infty} \lambda_{t+1}=0\right)$.

Notice that the growing economy does not need to be liquidity-scarce in the sense of Definition 3 to be constrained. Definition 3 corresponds to liquidity needs in a closedeconomy steady state with no growth. In an open economy, liquidity is available in infinite amounts on international markets. However, a growing economy can be constrained for 
any level of $\phi<1$ because growth generates a strong need for borrowing to smooth consumption.

If agents are initially unconstrained, they liquidate their assets progressively as $g$ goes to zero. If initial wealth is low, if $g$ converges to zero slowly and if credit constraints are stringent ( $\phi$ is small), then they eventually end up with binding constraints.

\section{Optimal policy}

The optimal policy crucially depends on the set of instruments available to the planner. As explained in Section 2, we first consider the case where the planner can change the supply of liquidity $B_{t}$ and holdings of international reserves $B_{t}^{*}$ but not the level of the distortive tax, which is fixed once and for all to $\tau$. The consumption $\operatorname{tax} \tau$ is then used to balance the intertemporal budget constraint of the central bank, but not to affect the intertemporal choices of the agents. In the next section, we consider the case where the planner can freely choose the level of the consumption tax $\tau_{t}-1$ every period.

We consider the optimal policy both in the steady state and in an economy converging to its steady state. In both cases, we find that it is optimal to accumulate reserves. Moreover, when the economy is away from its steady state, it is optimal to have $r_{t}$ diverge from $r^{*}$.

\subsection{The Ramsey Problem}

To analyze optimal policy we consider the Ramsey planner under the semi-open economy regime. The planner maximizes its objective (10) subject to the household budget constraints (2) and (3), their first order conditions (5) and (6), the credit constraint (4) and the aggregate resource constraint. The latter is found using the equilibrium on the bond market (8) and the agents' budget constraints. Maximization is carried out with

respect to $\left\{L_{t+1}, D_{t+1}, B_{t+1}^{*}, c_{t}^{D}, c_{t}^{L}, r_{t+1}\right\}_{t \geq 0}$. The Lagrangian of the Ramsey's problem in 
the semi-open economy is then defined as follows:

$$
\begin{aligned}
& \mathcal{L}=\sum_{t=0}^{\infty} \beta^{t}\left\{u\left(c_{t}^{D}\right)+u\left(c_{t}^{L}\right)\right. \\
& +\gamma_{t}^{D}\left[Y_{t}-\tau c_{t}^{D}-D_{t+1}-r_{t} L_{t}\right] \\
& +\gamma_{t}^{L}\left[a Y_{t}+r_{t} D_{t}+L_{t+1}-\tau c_{t}^{L}\right] \\
& +\gamma_{t}^{G}\left[r^{*} B_{t}^{*}-B_{t+1}^{*}+(1+a) Y_{t}-c_{t}^{D}-c_{t}^{L}\right] \\
& +\kappa_{t}^{D}\left[u^{\prime}\left(c_{t}^{D}\right)-\beta r_{t+1} u^{\prime}\left(c_{t+1}^{L}\right)\right] \\
& +\kappa_{t}^{L}\left[u^{\prime}\left(c_{t}^{L}\right)-\beta r_{t+1} u^{\prime}\left(c_{t+1}^{D}\right)\left(1+\lambda_{t+1}\right)\right] \\
& \left.+\Lambda_{t}\left[\phi Y_{t}-r_{t} L_{t}\right]\right\}
\end{aligned}
$$

To determine whether the planner wants to deviate from the open economy regime with $r=r^{*}$, we focus on the first order condition with respect to $r_{t+1}$ :

$$
\gamma_{t+1}^{L} D_{t+1}-\left(\gamma_{t+1}^{D}+\Lambda_{t+1}\right) L_{t+1}-\kappa_{t}^{D} u^{\prime}\left(c_{t+1}^{L}\right)-\kappa_{t}^{L} u^{\prime}\left(c_{t+1}^{D}\right)\left(1+\lambda_{t+1}\right)=0
$$

The first two terms reflect the direct distributive effects between depositors and borrowers (or cash-rich and cash-poor households). The last two terms reflect the effect of the interest rate on the intertemporal choices of households. These terms reflect the potential need for pigovian taxation.

Optimal policy obeys complex motives. In order to understand what the trade-offs of the central bank are, we proceed in two steps. First, we evaluate the above firstorder condition in an open economy with no central bank intervention in a constrained transition path as the one studied in the previous section. We then simulate the optimal semi-open regime, i.e., the one that satisfies the FOCs of the above Ramsey problem.

\subsection{Is the Open Economy Optimal?}

We define by $I_{t+1}^{*}$ the left-hand side of (16) evaluated at $r_{t+1}=r^{*}$. To determine whether $r_{t+1}$ should be lower or higher than $r^{*}$, we look at the sign of $I_{t+1}^{*}$. If $I_{t+1}^{*}$ is positive, then the central bank can increase social welfare by raising the interest rate. 
If $I_{t+1}^{*}$ is negative, then it can increase social welfare by lowering the interest rate. In general, any deviation of $I_{t+1}^{*}$ from zero means that the open economy is suboptimal.

First, we can show that, if the economy is constrained along the convergence path, $\kappa_{t}^{D}=\kappa_{t+1}^{L}=0$, for all $t \geq 0$. This means that there is no Pigovian tax after the first period. This is because distorting the households' intertemporal choices is ineffective when credit constraints are binding. As a result, $I_{t+1}^{*}$ is simply equal to the direct redistributive effect of the interest rate. Using the other FOCs of the planner's program, it can be written as follows for all $t \geq 1$ (see the Appendix for more details):

$$
I_{t+1}^{*}=\left(\sum_{i=1}^{\infty} \Lambda_{t+2 i}\right) D_{t+1}-\left(\sum_{i=0}^{\infty} \Lambda_{t+1+2 i}\right) L_{t+1}
$$

The first term corresponds to the net effect of the interest rate on depositors and is obviously positive. The second term corresponds to the net effect of the interest rate on loan issuers. This term is negative because a high interest rate hurts the households who issued loans in the previous period (the current cash-rich households) through higher interest payment, and makes the credit constraint more stringent for the cash-poor households.

The fact that $I_{t+1}^{*}$ is not necessarily equal to zero means that the decentralized allocation is not optimal and that the central bank can improve welfare. This comes from the fact that private agents are credit-constrained, which hinders the intratemporal and intertemporal allocation of resources. In that context, the planner, who faces no constraint, can use its available instruments to improve the allocation of resources. This justification for public intervention, and in particular for capital controls, is different from the externality view that has been put forward in the literature (Benigno et al., 2010, Korinek, 2010, Jeanne and Korinek, 2011).

According to Proposition 2, an open economy that is constrained on its transition path is unconstrained in the long run as long as its growth is asymptotically zero. This implies that $I_{t+1}^{*}$ converges to zero, as $\Lambda$ goes to zero. The central bank has no incentives to redistribute wealth by distorting the interest rate in the steady state as the utilities of the two groups of agents converge. This means that an open economy in the steady state 
is at the Ramsey optimum. This is because, as described in Corollary 2, this economy has accumulated a sufficient amount of reserves.

As argued above, in the open economy, it does not matter whether the accumulation of foreign assets takes place through reserve accumulation or private capital flows. In the long run, the open economy would still be optimal if private agents had the right to trade foreign bonds. However, in the transition, since $\Lambda>0, I_{t+1}^{*}$ can be either positive or negative, which means that the central bank has incentives to manipulate the domestic interest rate by setting capital controls and taking charge of the foreign trade in bonds. In that case, the accumulation of foreign bonds necessarily takes place through the central bank, even if capital controls are irrelevant in the long run.

The sign of $I_{t+1}^{*}$ depends on the relative size of $D_{t}$ and $L_{t}$ as well as on the evolution of the shadow cost of credit constraints, $\Lambda_{t}$. We can derive the following Lemma:

Lemma 1 If $\Lambda_{t+3}=\xi^{2} \Lambda_{t+1}$ for all $t \geq 1$, with $0 \leq \xi<1$, then $I_{t+1}^{*}$ is of the same sign as $D_{t+1} / L_{t+1}-\Lambda_{t+1} / \Lambda_{t+2}$ for all $t \geq 1$.

Proof. This Lemma derives directly from the definition of $I_{t+1}^{*}$. Indeed, $I_{t+1}^{*}=$ $\left(\Lambda_{t+2} D_{t+1}-\Lambda_{t+1} L_{t+1}\right) /\left(1-\xi^{2}\right)$.

The interpretation is as follows. The incentives for the central bank to raise the interest rate are strong if the amount of deposits is large as compared to the amount of loans, since $\left(r-r^{*}\right)(D-L)$ represent the net quantity of resources that will be distributed to households. On the other hand, $I_{t+1}^{*}$ is decreasing in the ratio between the shadow costs of the current and future credit constraints. Indeed, if the constraints faced by today's borrowers are more stringent than those faced by future borrowers (today's depositors), then it is better to transfer resources to the former by decreasing debt repayments.

When we consider the specific process for converging endowments described in (15), we can derive the following proposition.

Proposition 3 Consider an open economy with $\beta r^{*}=1$ and no taxes $(\tau=1)$ that is constrained in $t$, with $g_{t}$ small. If $g_{t+1}=\mu g_{t}, 0 \leq \mu<1, g_{t}>0$, then $I_{t+1}^{*}$ is of the same sign as $\frac{1-a}{(1+1 / \mu)(1+\beta)}-\phi$. 
As mentioned, the sign of $I_{t+1}^{*}$ is ambiguous and depends both on the size of loans $L$ as compared to the size of deposits $D$ and on the size of $\Lambda_{t+1}$ as compared to $\Lambda_{t+2}$. The size of $\Lambda_{t+1}$ as compared to $\Lambda_{t+2}$ is governed by $\mu$. When $\mu$ is small, the convergence speed of $g$ is high and future constraints are less stringent than the current ones. In that case, it is optimal for the central bank to decrease the domestic interest rate in order to subsidize the currently constrained agents. When $\mu$ is large, growth is sustained, and future constraints are stringent. In that case, the central bank might want to increase the interest rate to subsidize the agents who will be constrained in the future and who are currently holding deposits. However, $I_{t+1}^{*}$ also depends on $D / L$, which is governed by $\phi$ and $a$. If $\phi$ and $a$ are small enough, the liquidity needs of cash-poor households are strong and the central bank can still have an incentive to increase the interest rate. In general, whether $I_{t+1}^{*}$ is positive or negative, the open economy regime is suboptimal on a constrained transition path.

To better understand the intuition of the result in Proposition 3, it is useful to consider two limit cases, corresponding to an economy of either borrowers or lenders only. Consider first the limit $a \rightarrow 1$ (all households receive the same endowment): in that case, the model reduces to a standard representative agent. This representative agent is prevented by the binding borrowing constraint to consume early on its growing future endowment. The planner can help by decreasing the interest rate, which amounts to subsidize borrowing. This alleviates the borrowing constraint and helps the household transfer resources from the next to the current period. According to Proposition 3, the sign of $I_{t+1}^{*}$ is indeed strictly negative when $a \rightarrow 1$. A similar result arises when $\mu \rightarrow 0$. In that case, the constraint lasts only one period. The objective of the planner is simply to alleviate today's constraint, and it is then optimal to decrease the interest rate.

Consider next the limit $\phi \rightarrow 0$, in which no borrowing is possible. Then lenders try to accumulate assets to transfer resources from the cash-rich to their cash-poor periods. As shown in Corollary 2, in a steady state at the world interest rate, they can accumulate enough assets to fully self-insure against income fluctuations. Then, the borrowing constraint does not bind and the central planner cannot improve on the open economy. 
However, with a growing endowment the world interest rate is not large enough to allow lenders to accumulate enough assets. Then, the planner can help by increasing the interest rate above its world level, which amounts to subsidizing saving. According to Proposition 3 , the sign of $I_{t+1}^{*}$ is indeed strictly positive when $\phi \rightarrow 0$, and all the more so as growth is sustained, i.e. as $\mu$ is large.

\subsection{The Ramsey Policy}

The basic conclusion is that it is generally optimal to set $r_{t} \neq r^{*}$, i.e., to deviate from the open economy regime. ${ }^{11}$ The actual optimal policy, however, cannot be derived analytically so that we simulate the semi-open economy under the Ramsey policy, with different parameter specifications. ${ }^{12}$ The resulting optimal interest rates are shown in Figure 3. In the baseline, we set $\mu=0.4, a=0$ and $\phi=0.1$. At $t=0$, the economy is supposed to be in a steady state where $\frac{B}{Y}=\beta\left(\frac{1-a}{1+\beta}-2 \phi\right)$ so that the borrowing constraint is (marginally) non-binding. At $t=1$, the economy start growing at an initial rate of $10 \%$. This case generates a higher interest rate in the transition to the steady state, as the convergence speed is low and liquidity needs are strong. We then lower $\mu$ to 0.1. The figure shows that, as predicted by Proposition 3, the central bank has then an incentive to lower the interest rate. The picture is the same when we raise $\phi$ to 0.2 and $a$ to 0.5 .

Figure 4 gives the dynamics of the semi-open economy in the baseline case where growth is sustained and liquidity needs are strong and compares it with the open economy. In this case, borrowers at the beginning of the growth episode suffer because the high interest rate makes their constraint more stringent and increases their debt repayments ( $c^{L}$ is below its open-economy value). Consistently, they borrow less than in the open economy. But later, borrowers benefit from the larger return of their liquid assets.

\footnotetext{
${ }^{11}$ Strictly speaking, the optimal policy could also consist in adjusting the tax rate $\tau$. For example, the government might want to decrease $\tau$ to transfer resources to constrained agents. However, this can easily violate the government intertemporal budget constraint. In that example, the government would need to decrease the domestic interest rate to generate resources. In our simulations, this was however never a solution. This is because decreasing the interest rate makes the credit constraints more stringent, necessitating a further decrease in $\tau$, which again imposes a decrease in the interest rate.

${ }^{12}$ The model is simulated with DYNARE (Adjemian et al., 2011).
} 
Depositors consume slightly less than in the open economy because they have to spend more on interest payments. This policy is welfare-improving because future constraints are stringent and the demand for deposits is large as compared to the demand for loans: increasing the return on liquid assets alleviates future constraints without making the current ones excessively stringent. To increase the domestic interest rate, the Central Bank increases the supply of public bonds $B$. In the short run, reserve accumulation is also faster. But in the long run, because this policy is costly (more interest on public bonds have to be paid), the level of reserves is lower.

Figure 5 gives the dynamics with a more short-lived growth and stronger liquidity needs (we set $\mu=0.3$ and $\phi=0.2$ ). In this case, borrowers benefit from the lower interest rate at the beginning of the growth episode as they can borrow more. But later, they suffer from the lower return on their liquid assets. Depositors consume more because they pay less interests on their debt. This policy is welfare-improving because credit constraints are front-loaded, so it is more efficient to alleviate the current constraints by lowering the interest rate. Besides, the demand for loans is large as compared to the demand for liquidity. The central bank can therefore transfer more resources to the agents by decreasing the interest rate. To decrease the domestic interest rate, the Central Bank decreases the supply of public bonds. This translates into a slower reserve accumulation in the short run. But in the long run, since this policy creates additional resources for the central bank (the central bank pays a lower interest rate on its debt), the country accumulates more external reserves.

\section{Optimal Policy with Flexible Tax Rates}

Giving more instruments to the planner may drastically change the optimal policy. In this section, we consider the case where the planner can choose the optimal tax rate of consumption $\tau_{t}-1$ at each period. On a transition path, it is still optimal to have $r_{t} \neq r^{*}$, but it is no longer optimal to accumulate reserves. This is because the set of taxes is complete, but not redundant. The domestic interest rate and the consumption tax are 
sufficient to replicate the first best, so reserve accumulation is not needed anymore to overcome the credit constraints. A growing economy actually becomes a net debtor, as in the first best. But the government is compelled to use the domestic interest rate in the absence of an alternative tax.

When the planner has the full use of the consumption tax, it can actually overcome the borrowing constraint and transfer consumptions both across periods and across households. It can thus achieve a first best allocation where borrowing constraints never bind and the marginal utility of consumption is constant both across periods and households. With a growing endowment as in (15), the planner adjusts the tax rate (potentially negative) so that households consume part of their future income and have a constant consumption. In this process, the planner borrows abroad (or depletes foreign reserves). This case is described in the following proposition.

Proposition 4 Consider an endowment stream $\left\{Y_{t}\right\}_{t \geq 0}$, initial conditions $r_{0} D_{0}, r_{0} L_{0}$, $B_{0}^{*}$, with $r_{0} L_{0}<Y_{0}$, and a real number $\rho>0$. There exists a sequence of policy instruments $\left\{B_{t+1}, B_{t+1}^{*}, \tau_{t}\right\}_{t \geq 0}$ such that in the corresponding decentralized equilibrium borrowing constraints never bind, each household has a constant consumption, and the ratio of consumptions for both types of households is equal to $c_{0}^{L} / c_{0}^{D}=\rho$.

Proof. See Appendix E.

As the Proposition shows, the planner can achieve any allocation such that the borrowing constraints do not bind and the ratio of consumptions for both types of households stays constant. In particular, it can choose the same level of consumption for both types of households by setting $\rho=1$ : this allocation maximizes the welfare function (10). Although this does not necessarily maximize welfare, the planner can also replicate the open economy with no borrowing constraints by setting an appropriate ratio $\rho$. This implies that the planner can always Pareto-improve on the open economy with (potentially) binding constraints.

The proof of the Proposition consists in explicitly constructing the family of allocations with constant consumptions and lax constraints. Intuitively, the planner can tax 
or subsidize consumption to transfer wealth across agents and periods. Subsidies are financed by borrowing abroad or depleting reserves and the product of taxes can be saved by buying foreign reserves. However, as can be seen from equations (5) and (6), changes in the tax rate distort the Euler equation of households. To make sure that agents choose a constant consumption stream, the planner has to move the domestic real interest rate away from the world interest rate so that the tax-adjusted interest rate $r_{t+1} \tau_{t} / \tau_{t+1}$ stays equal to the world rate. Thus, in general, the optimal policy requires the economy to deviate from the open economy, as shown in the following Corollary.

Corollary 3 Consider an endowment stream $\left\{Y_{t}\right\}_{t \geq 0}$, initial repayments on deposits and loans $r^{*} D_{0}$ and $r^{*} L_{0}$, and initial foreign reserves $B_{0}^{*}=D_{0}-L_{0}$ such that the borrowing constraint binds at some date $t \geq 0$ in the open economy with zero taxes (i.e. with $\left.\tau_{t}=1, \forall t \geq 0\right)$. Then, along the optimal policy, $r_{t}$ deviates from $r^{*}$ for some date $t$.

Proof. We know from Proposition 4 that optimal policy requires lax constraints and constant consumption. Then, compared with the open economy with no taxes, optimal policy requires either a change in the tax rate or in the domestic interest rate. Also, from the first order conditions (5) and (6), we must have $r_{t+1} \tau_{t}=r^{*} \tau_{t+1}$. Suppose the domestic interest rate stays equal to $r^{*}$. Then the tax rate can only change once and for all at $t=0$. From the government budget constraint (9), this implies that $B_{t}^{*}$ will diverge either to $+\infty$ or $-\infty$. The former is not optimal. The latter violate the upper limit on net foreign debt. We conclude that the domestic interest rate has to diverge from the world interest rate.

This case provides another justification for imposing capital controls during the convergence to the steady state. In the previous section, it was the binding constraint and absence of tax instruments that justified a different interest rate. In this section, the justification comes from distortionary taxes. The planner needs the domestic interest rate to deviate from the world interest rate to offset the distortionary effect of the tax. But if the planner had access to an alternative tax, like a tax on the interest rate, distorting the domestic interest rate through capital controls would not be necessary. Notice that both reasons disappear once we reach a steady state (assuming $\beta r^{*}=1$ ). As a conclusion, both 
the recourse to reserve accumulation and capital controls arise as a result of incomplete taxation.

Figure 6 shows an example of optimal policy when taxes are flexible and compares it to the case where they are not in an economy on the convergence path described by (15). The parameters are set to their baseline values $(\mu=0.4, a=0, \phi=0.1)$. When taxes are flexible, the planner sets a large subsidy in the first period so that consumption jumps to its constant first best level, and taxes consumption later on. It also issues bonds, allowing agents to save part of their subsidy to overcome the borrowing constraints in the subsequent periods. This raises the domestic interest rate and exactly offset the future increase in tax rates in households' Euler equations. As the economy, in the aggregate, consumes the permanent value of its growing endowment from the start, this policy requires running a current account deficit during the transition: foreign reserves decrease.

\section{Accumulation of Reserves and Capital Controls in China}

Since the paper is motivated by developments in the Chinese economy in the last decade, it is interesting to compare the implications of the model with these developments. First, consider our basic assumptions. China has strict limits to capital mobility, in particular on outflows, while the central bank is very active on international capital markets. This corresponds well to the semi-open economy. Moreover, most households and firms have very limited access to finance. It is well known that state-owned enterprises receive most of the banks' credit. In addition, the potential need for funds is high, due for example to a lack of a social safety net or to various life-cycle considerations in a fast-growing economy, e.g., funding for education, starting own business projects (e.g., see Yang et al., 2011). In the empirical literature, income uncertainty and poor access to finance in China are actually considered as the main drivers of the high private saving rate in that country and of global imbalances (IMF, 2009, Chamon and Prasad, 2010, 
Forbes, 2009). Another important assumption is the high and sustained growth rate. China experienced an average growth rate of $10 \%$ from 2001 to 2010.

The first implication of our model is that it is optimal for the central bank to issue liquidity to the private sector and to accumulate international reserves. This is exactly what Figures 1 and 2 show. Thus, the accumulation of reserves of the Chinese central bank can be part of an optimal plan, even though our model is too stylized to determine quantitatively whether the magnitude of reserves accumulation is optimal.

The other implication is that it is optimal to impose capital controls so that the domestic interest rate can differ from the foreign rate. Our model predicts that in the Chinese context it is optimal to keep the domestic interest rate temporarily higher than the international one. Indeed, it appears reasonable to characterize the Chinese economy with a low value of $\phi$, reflecting tight credit constraints, a low value of $a$, reflecting high level of income uncertainty and heterogeneity, and a high value for $\mu$, reflecting sustained growth. If we consider Proposition 3, the combination of low $\phi$ and $a$ and high $\mu$ imply that a high interest rate is desirable. This implies an accumulation of reserves that is larger than what would happen in an open economy. Intuitively, with growth expected to stay high in the coming years, China should worry that the private sector might face strong funding constraints for consumption or investment needs for a long time. Increasing the interest rate on saving instruments should then help the private sector accumulate assets to fund those future needs.

Comparing the models' implications with Chinese interest rate policy is tricky because our theory abstracts from various aspects such as inflation, nominal exchange rates, spreads between loan and deposit rates, term spreads, etc. However, it is safe to argue that the policy observed in China in the last decade does not correspond to the optimal policy produced by our model. If anything, Chinese authorities are notorious for trying to keep interest rates on saving instruments (such as deposits) at a low level through several channels, including moral suasion (Green, 2005). Our results suggests that this policy is not socially optimal. It helps current borrowers at the expense of future borrowers who should be favored instead. Actually, this policy aims at subsidizing loans to state-owned 
enterprises (Fung et al., 2000, Laurens and Maino, 2007), which are less credit-constrained than private firms. This means that not only does this policy fail at transferring resources to depositors, but it also fails at alleviating the current credit constraints of borrowers.

Our theory does not feature a spread between loan and deposit rates, but it suggests that this spread should be kept to a minimum. However, the four state-owned commercial banks have a quasi monopoly in China's financial market (Wong and Wong, 2001, Berger and al., 2009). This situation is likely to maintain monopoly rents that inflate the spread between loan and deposit rates. Besides, despite the substantial interest rate liberalization that took place in October 2004, the authorities still impose a ceiling on deposit rates and a floor on lending rate as a means to preserve intermediation margins (Laurens and Maino, 2007). This policy maintains a lower bound on the spread, which is suboptimal because it generates rents, but also because it further hinders the optimal allocation of resources according to our model, even though it might be partly justified by the mitigation of credit risk. In practice, it seems that these measures are effective in maintaining low interest rates on deposits. This is evident from the fact that the People's Bank of China has managed to contain the cost of sterilization operations associated with international reserves accumulation, and even to make benefits (Green, 2005, Laurens and Maino, 2007).

\section{Conclusion}

This paper has analyzed optimal policy in a semi-open economy, where the Ramsey planner is a central bank that has access to international capital markets. We found that the accumulation of reserves combined with capital controls gives a higher welfare than full capital mobility in a rapidly growing economy. This characterization clearly corresponds to the Chinese economy. On the other hand, we found that it would be optimal to have high interest rates on saving instruments, which is different from what is observed in China.

The accumulation of assets by a Ramsey planner when consumers are credit con- 
strained may be surprising. Indeed it would seem more intuitive if the planner would borrow in the international market as an intermediary for the consumers. This would actually correspond to the first best allocation in a converging phase, as shown in Section 5. But with a limited set of instruments, the central bank is not able to relax the credit constraint and the optimal policy is lend to, rather than borrow from, the rest of the world.

Changes in foreign exchange reserves are naturally associated with exchange rate policy. In our context, the exchange rate does not play a role as the analysis is conducted in a one-good economy. A natural extension is to add traded and non-traded goods. In such an extension, international reserve accumulation obviously goes in parallel with a real depreciation (see Jeanne, 2011). Consequently, a real depreciation would be optimal if reserve accumulation is. However, this would only be the case in a transition phase. As the economy approaches its steady state, a higher level of reserves should lead to an appreciated currency.

Another interesting extension would be to model explicitly the domestic financial sector. This would give more instruments to the central bank. For example, central bank liabilities are made of commercial banks' reserves and of central bank bonds. The central bank can typically adjust the interest rate on reserves as well as the reserve requirements. However, reserve requirements do not seem useful in our context as it is optimal to have high interest rate on deposits. 


\section{References}

Adjemian, S., H. Bastani, M. Juillard, F. Mihoubi, G. Perendia, M. Ratto and S. Villemot (2011), "Dynare: Reference Manual, Version 4", Dynare Working Papers, 1, CEPREMAP.

Aiyagari, S. R. and E.R. McGrattan (1998), "The Optimum Quantity of Debt," Journal of Monetary Economics 42, 447-469.

Aiyagari, S. R., A. Marcet, T.S. Sargent, and J. Sepälä (2002), "Optimal Taxation without State-Contingent Debt," Journal of Political Economy 110, 1220-1254.

Aizenman, J. (2011), "Hoarding International Reserves versus a Pigovian Tax-cumSubsidy Scheme: Reflections on the Deleveraging Crisis of 2008-2009, and a cost benefit analysis," Journal of Economic Dynamics and Control 35, 1502-1513.

Aizenman, J. and J. Lee (2007), "International Reserves: Precautionary versus Mercantilist Views, Theory and Evidence," Open Economies Review 18, 191-214.

Bacchetta, Ph. and K. Benhima (2010), "The Demand for Liquid Assets, Corporate Saving, and Global Imbalances," mimeo.

Barnichon, R. (2009), "The Optimal Level of Reserves for Low-Income Countries: SelfInsurance against External Shocks," IMF Staff Papers 56, 852-875.

Benigno, G., H. Chen, C. Otrok, A. Rebucci, and E. R. Young (2010), "Financial Crises and Macro-Prudential Policies," mimeo.

Benigno, G., H. Chen, C. Otrok, A. Rebucci, and E. R. Young (2011), "Optimal Policy for Macro-Financial Stability," mimeo.

Berger, A. N., I. Hasan and M. Zhou (2009), "Bank ownership and efficiency in China: What will happen in the world's largest nation?", Journal of Banking and Finance 33 $113-130$ 
Bianchi, J. (2011), "Overborrowing and Systemic Externalities in the Business Cycle," American Economic Review, forthcoming.

Bianchi, J. and E. Mendoza (2010), "Overborrowing, Financial Crises and 'Macroprudential' Policy," mimeo.

Dooley M, Folkerts-Landau D, Garber P (2003), "An essay on the revived Bretton Woods System," NBER Working paper No. 9971.

Durdu, B., E. Mendoza, and M. Terrones (2009), "Precautionary Demand for Foreign Assets in Sudden Stop Economies: An Assessment of the New Merchantilism," Journal of Development Economics 89, 194-209.

Frenkel, J. and B. Jovanovic (1981), "Optimal International Reserves: A Stochastic Framework," Economic Journal 91, 507-514.

Caballero, R. J., E. Farhi and P.-O. Gourinchas (2008), 'An equilibrium model of "global imbalances" and low interest rates', American Economic Review 98(1), 358-93.

Chamon, M. and E. Prasad (2010), "Why are Saving Rates of Urban Households in China Rising", American Economic Journal: Macroeconomics.

Forbes, K. (2010), "Why do Foreigners Invest in the United States?", Journal of International Economics 80(1): 3-21.

Fung, M. K-Y., W-M. Ho and L. Zhu (2000) "The Impact of Credit Control and Interest Rate Regulation on the Transforming Chinese Economy: An Analysis of Long-Run Effects", Journal of Comparative Economics 28, 293-320

Green, S. (2005), "Making monetary policy work in China: A report from the money market front line", Stanford Center for International Development Working Paper, vol. 245.

Holmstrom, B. and J. Tirole (2001), 'LAPM: A liquidity-based asset pricing model', Journal of Finance 56(5), 1837-67. 
Holmstrom, B. and J. Tirole (2002), "Domestic and International Supply of Liquidity," American Economic Review, American Economic Association, vol. 92(2), pages 42-45.

Holmstrom, B. and J. Tirole (2011), Inside and Outside Liquidity, MIT Press.

International Monetary Fund (2009), Regional Economic Outlook: Asia and Pacific.

Jeanne, O. (2011), "Capital Account Policies and the Real Exchange Rate," mimeo.

Jeanne, O. and A. Korinek (2011), "Managing Credit Booms and Busts: A Pigouvian Taxation Approach," mimeo.

Jeanne, O. and R. Rancière (2011), "The Optimal Level of International Reserves For Emerging Market Countries: a New Formula and Some Applications," Economic Journal, forthcoming.

Juillard, M. (1996), "Dynare: A program for the resolution and simulation of dynamic models with forward variables through the use of a relaxation algorithm", CEPREMAP, Couverture Orange, 9602.

Korinek, A. (2010), "Regulating Capital Flows to Emerging Markets: An Externality View," mimeo.

Laurens, B. J. and R. Maino (2007), "China: Strengthening Monetary Policy Implementation", IMF Working Paper WP/07/14

Mendoza, E. G., V. Quadrini and J.-V. Ríos-Rull (2009), 'Financial integration, financial development, and global imbalances', Journal of Political Economy 117(3), 371-416.

Obstfeld, M., J. C. Shambaugh, and A. M. Taylor (2011), "Financial Stability, the Trilemma, and International Reserves," American Economic Journal Macroeconomics, forthcoming.

Shin, Y. (2006), "Ramsey Meets Bewley: Optimal Government Financing with Incomplete Markets," mimeo. 
Song, Z.M., K. Storesletten and F. Zilibotti (2010), 'Growing like China', American Economic Review, forthcoming.

Wen, Y. (2011), "Making Sense of China's Excessive Foreign Reserves," Federal Reserve Bank of St Louis Working Paper 2011-006A.

Wong, Y. C. R. and M. L. S. Wong (2001), "Competition in China's Domestic Banking Industry", Cato Journal, Vol. 21, No. 1

Woodford, M. (1990), 'Public debt as private liquidity', American Economic Review $80(2), 382-88$.

Yang, D.T., J. Zhang, and S. Zhou (2011), "Why Are Saving Rates so High in China?" NBER Working Paper No. 16771. 


\section{A Proof of Proposition 1}

Assume first that the borrowing constraint is binding. Then, using the expression for deposits (13) and loans (14) in the steady state, the bond market equilibrium (8) can be written $P(1 / r)=0$, with

$$
P(X)=\phi X^{2}+[a+\phi(1+\beta)] X-\left[\beta(1-\phi)-(1+\beta) \frac{B}{Y}\right]
$$

It is easy to see that $P(\beta)<0$ if and only if $\frac{B}{Y}<\beta\left(\frac{1-a}{1+\beta}-2 \phi\right)$. In that case, there is a unique positive equilibrium interest rate $r<1 / \beta$. This equilibrium interest rate is an increasing function of $\frac{Y}{B}$. The ratio of relative consumption is given by the first order condition (5). The other first order condition, equation (6), implies that the constraint must be binding when $r<\beta$.

Assume now that the borrowing constraint does not bind. From the first order conditions (5) and (6), it is clear that we must have $\beta r=1$ so that consumption will be constant for both types of households. In a symmetric steady state, it follows that $c^{L}=c^{D}$. Then, taking the difference of budget constraints (2) and (3) in the steady state, together with the bond market equilibrium (8), we get $2 L=\frac{\beta}{1+\beta}(1-a) Y-B$. The condition such that the constraint does not bind is $L \leq \beta \phi Y$, which becomes $\frac{B}{Y} \geq \beta\left(\frac{1-a}{1+\beta}-2 \phi\right)$.

\section{B Proof of Proposition 2}

We denote by $\tilde{X}=X / Y$ the normalized variables. Take an agent who is constrained in $t-2$, her cash-poor period. We look for conditions under which the agent is constrained for all $t+2 k$ and unconstrained for all $t+2 k+1, k \geq 0$. We assume that such conditions exist and derive an expression for $\lambda_{t+2 k+1}$. We then derive conditions under which $\lambda_{t+2 k+1}>0$ for all $k \geq 0$ and $\tilde{D}_{t+2 k+1} \geq 0$.

If the agent is constrained for all $t+2 k$ and unconstrained for all $t+2 k+1, k \geq 0$, then:

$$
\tilde{c}_{t+2 k}^{L}=\frac{1}{1+\beta}\left[\frac{1-\phi}{1+g_{t+2 k}}+\beta a+\beta^{2} \phi\left(1+g_{t+2 k+1}\right)\right]
$$




$$
\tilde{c}_{t+2 k+1}^{D}=\frac{1}{1+\beta}\left[(1-\phi)+\beta a\left(1+g_{t+2 k+2}\right)+\beta^{2} \phi\left(1+g_{t+2 k+2}\right)\left(1+g_{t+2 k+3}\right)\right]
$$

Equations (18) and (19) are found by combining the budget constraint (2) and (3) with (13) and (14).

We then use the Euler equation (6) and $\beta r^{*}=1$ to derive the multiplier of the credit constraint:

$$
\begin{aligned}
1+ & \lambda_{t+2 k+1}=\left(1+g_{t+2 k+1}\right) \frac{\tilde{c}_{t+2 k+1}^{D}}{\tilde{c}_{t+2 k}^{L}} \\
& =\left(1+g_{t+2 k}\right)\left(1+g_{t+2 k+1}\right) \frac{1-\phi+\left(1+g_{t+2 k+2}\right) \beta a+\left(1+g_{t+2 k+2}\right)\left(1+g_{t+2 k+3}\right) \beta^{2} \phi}{1-\phi+\left(1+g_{t+2 k}\right) \beta a+\left(1+g_{t+2 k}\right)\left(1+g_{t+2 k+1}\right) \beta^{2} \phi}
\end{aligned}
$$

Using the fact that $g_{t+k}=\mu^{k} g_{t} \simeq 0$, we approximate:

$$
\lambda_{t+2 k+1} \simeq g_{t+2 k}(1+\mu) \frac{1-\phi+\mu \beta a+\mu^{2} \beta^{2} \phi}{1-\phi+\beta a+\beta^{2} \phi}
$$

As long as $\phi<1, \lambda_{t+2 k+1}>0$ for all $k \geq 0$. This implies that agents are constrained in all their cash-poor periods.

Finally, we check whether the agents are unconstrained in all their cash-rich periods. We have:

$$
\tilde{D}_{t}=\frac{1}{1+\beta}\left[\beta \frac{1-\phi}{1+g_{t}}-\beta a-\beta^{2} \phi\left(1+g_{t+1}\right)\right]
$$

For the agents not to be constrained in their cash-rich periods, we must have $\tilde{D}_{t} \geq-\beta \phi$. For $g$ small, this amounts to $a \leq 1$, which is a parametric assumption.

\section{Derivation of equation 17}

For $t \geq 0$, by taking the derivative of the Lagrangian $\mathcal{L}$ with respect to $\lambda_{t+1}$, we can show that $\kappa_{t}^{L}=0$. Using the central bank FOCs, we now show that $\kappa_{t+1}^{L}=0$ implies $\kappa_{t}^{D}=0$. Differentiating with respect to reserves gives, with $\beta r^{*}=1$ :

$$
\gamma_{t}^{G}=\gamma_{t+1}^{G}
$$


The first-order conditions with respect to $D$ and $L$ are, with $r=r^{*}$ :

$$
\begin{gathered}
\gamma_{t}^{D}=\gamma_{t+1}^{L} \\
\gamma_{t}^{L}=\gamma_{t+1}^{D}+\Lambda_{t+1}
\end{gathered}
$$

The planner FOC with respect to $c_{t}^{D}$ and $c_{t+1}^{L}$ are the following:

$$
\begin{gathered}
u^{\prime}\left(c_{t}^{D}\right)-\gamma_{t}^{D}+\kappa_{t}^{D} u^{\prime \prime}\left(c_{t}^{D}\right)-\gamma_{t}^{G}=0 \\
u^{\prime}\left(c_{t+1}^{L}\right)-\gamma_{t+1}^{L}+\kappa_{t+1}^{L} u^{\prime \prime}\left(c_{t+1}^{L}\right)-\gamma_{t+1}^{G}=0
\end{gathered}
$$

From equation (5), we know that $u^{\prime}\left(c_{t}^{D}\right)=u^{\prime}\left(c_{t+1}^{L}\right)$. Combining with the above equations, we obtain:

$$
\gamma_{t+1}^{L}+\gamma_{t+1}^{G}-\kappa_{t+1}^{L} u^{\prime \prime}\left(c_{t+1}^{L}\right)=\gamma_{t}^{D}+\gamma_{t}^{G}-\kappa_{t}^{D} u^{\prime \prime}\left(c_{t}^{D}\right)
$$

Using the planner FOCs with respect to $D_{t+1}$ and $B_{t+1}^{*}$, we get:

$$
\kappa_{t+1}^{L} u^{\prime \prime}\left(c_{t+1}^{L}\right)=\kappa_{t}^{D} u^{\prime \prime}\left(c_{t}^{D}\right)
$$

Since $\kappa_{t+1}^{L}=0$ and $u^{\prime \prime}<0$, then $\kappa_{t}^{D}=0$ for all $t \geq 0$. This yields, for $t \geq 1$ :

$$
I_{t+1}^{*}=\gamma_{t+1}^{L} D_{t+1}-\left(\gamma_{t+1}^{D}+\Lambda_{t+1}\right) L_{t+1}
$$

Using the planner FOCs with respect to $D$ and $L$, we solve this equation forward and obtain:

$$
I_{t+1}^{*}=\left(\gamma_{\infty}^{L}+\sum_{i=1}^{\infty} \Lambda_{t+2 i}\right) D_{t+1}-\left(\gamma_{\infty}^{D}+\sum_{i=0}^{\infty} \Lambda_{t+1+2 i}\right) L_{t+1}
$$

Since the economy is asymptotically unconstrained according to Proposition 2, we have $\gamma_{\infty}^{L}=\gamma_{\infty}^{D}=\gamma_{\infty}$, as implied by equations (21) and (22). Therefore, we have:

$$
I_{t+1}^{*}=\left(\sum_{i=1}^{\infty} \Lambda_{t+2 i}\right) D_{t+1}-\left(\sum_{i=0}^{\infty} \Lambda_{t+1+2 i}\right) L_{t+1}+\gamma_{\infty}\left(D_{t+1}-L_{t+1}\right)
$$


for all $t \geq 0$. Taking $t$ to infinity, we obtain:

$$
\lim _{t \rightarrow \infty} I_{t+1}^{*}=\gamma_{\infty}\left(D_{\infty}-L_{\infty}\right)
$$

Combining $\gamma_{\infty}^{L}=\gamma_{\infty}^{D}=\gamma_{\infty}$ with equations (23) and (24) in the steady state, we derive: $u^{\prime}\left(c_{\infty}^{D}\right)=u^{\prime}\left(c_{\infty}^{L}\right)$. This allocation is the social planner solution, that is, it is the solution to the maximization of (10) under the aggregate budget constraint alone. This means that, in the steady state, the government cannot achieve a higher welfare by manipulating the interest rate. Therefore, $\lim _{t \rightarrow \infty} I_{t+1}^{*}=0$, which means that, as long as $D_{\infty}-L_{\infty} \neq 0$, the social cost of the individual budget constraints is zero in the long run, that is $\gamma_{\infty}=0$. Equation (17) is therefore always valid, either because $\gamma_{\infty}=0$ or because $D_{\infty}-L_{\infty}=0$.

\section{Proof of Proposition 3}

According to Proposition 2, an economy with binding credit constraint and $g_{t+1}=\mu g_{t}$ for all $t \geq 0$ satisfies $\lambda_{t+2 k+1} \simeq \mu^{2 k}(1+\mu) \frac{1-\phi+\mu \beta a+\mu^{2} \beta^{2} \phi}{1-\phi+\beta a+\beta^{2} \phi} g_{t}$ for all $k \geq 1$. To derive Lemma 1, we need to relate $\Lambda$ to $\lambda$. We use equations (20)-(24) and the households' Euler equations to achieve that.

Using equation (23) expressed in period $t+1$ and equation (24) expressed in period $t, t \geq 1$, and using $\kappa_{t}^{D}=\kappa_{t}^{L}=0$, we derive:

$$
u^{\prime}\left(c_{t}^{L}\right)-u^{\prime}\left(c_{t+1}^{D}\right)-\gamma_{t}^{L}+\gamma_{t+1}^{D}-\gamma_{t}^{G}+\gamma_{t+1}^{G}=0
$$

Using equations (20)-(22) and the Euler equation for the cash-poor agent, we obtain:

$$
u^{\prime}\left(c_{t+1}^{D}\right) \lambda_{t+1}=\Lambda_{t+1}
$$

With log-utility, we have:

$$
\frac{\Lambda_{t+1}}{\Lambda_{t+2}}=\frac{\lambda_{t+1}}{\lambda_{t+2}} \frac{\left(1+g_{t+2}\right) \tilde{c}_{t+2}^{D}}{\tilde{c}_{t+1}^{D}}
$$


When $g$ is small, this can be approximated as follows:

$$
\frac{\Lambda_{t+1}}{\Lambda_{t+2}} \simeq \frac{1}{\mu}
$$

This means that $\Lambda_{t+3}=\mu^{2} \Lambda_{t+1}$ for all $t \geq 1$, which, according to Lemma 1 , implies that $I_{t+1}^{*}$ is of the same sign as $D_{t+1} / L_{t+1}-\Lambda_{t+1} / \Lambda_{t+2} \simeq D_{t+1} / L_{t+1}-1 / \mu$

Finally, we can approximate:

$$
\frac{D_{t+1}}{L_{t+1}}=\frac{\frac{1}{1+\beta}\left[\beta \frac{1-\phi}{1+g_{t+1}}-\beta a-\beta^{2} \phi\left(1+g_{t+2}\right)\right]}{\beta \phi} \simeq \frac{1-a}{(1+\beta) \phi}-1
$$

This implies that $I_{t+1}^{*}$ is of the same sign as $D_{t+1} / L_{t+1}-1 / \mu \simeq(1-a) /(1+\beta) \phi-1-1 / \mu$ for all $t \geq 1$.

\section{E Proof of Proposition 4}

The proof of Proposition 4 proceeds by construction and consists in three steps.

1. Lemma 2 establishes that an equilibrium allocation corresponding to an endowment stream and a certain class of policy instruments is also the equilibrium allocation of the open economy with zero tax corresponding to a modified stream of endowments. In the following, we refer to this open economy environment as "the associated open economy problem".

2. We show how the planner can choose a sequence of policy instruments to get a stream of endowments in the associated open economy problem such that the borrowing constraint never binds and the ratio of consumption between both types of agents equals an arbitrary strictly positive number $\rho$.

3. From Lemma 2 this allocation also obtains in the semi-open economy with the chosen set of policy instruments.

Lemma 2 Consider an endowment stream $\left\{Y_{t}\right\}_{t \geq 0}$, and initial conditions $r_{0} D_{0}, r_{0} L_{0}$, $B_{0}^{*}$. Consider a set of policy instruments $\left\{\bar{B}_{t+1}, \bar{B}_{t+1}^{*}, \bar{\tau}_{t}\right\}_{t \geq 0}$ that satisfy the central bank's 
budget constraint (9), and such that

$$
\sum_{t \geq 0} \frac{1}{\left(r^{*}\right)^{t}}\left[(1+a) \frac{Y_{t}}{\bar{\tau}_{t}}\right]+r_{0} \frac{D_{0}-L_{0}}{\bar{\tau}_{0}}=\sum_{t \geq 0} \frac{1}{\left(r^{*}\right)^{t}}\left[(1+a) Y_{t}\right]+r^{*} B_{0}^{*}
$$

and that $r_{t+1} \frac{\overline{\bar{\tau}}_{t}}{\overline{\bar{\tau}}_{t+1}}=r^{*}$. Let $\left\{\bar{c}_{t}^{D}, \bar{c}_{t}^{L}\right\}_{t \geq 0}$ denote the corresponding equilibrium allocation. Then, $\left\{\bar{c}_{t}^{D}, \bar{c}_{t}^{L}\right\}_{t \geq 0}$ is also the decentralized equilibrium associated to the open economy regime, the sequence of taxes $\tau_{t}=1, \forall t \geq 0$, the endowment stream $\left\{\frac{Y_{t}}{\overline{\bar{\tau}}_{t}}\right\}_{t \geq 0}$, and initial deposits and loans $r^{*} \frac{D_{0}}{\tau_{0}}$ and $r^{*} \frac{L_{0}}{\tau_{0}}$.

The intuition of the lemma is the following: from the point of view of a household, it is equivalent

1. to have an initial wealth $W_{0}$, an endowment stream $\left\{Y_{t}\right\}_{t \geq 0}$, face a sequence of interest rates $\left\{r_{t+1}\right\}_{t \geq 0}$ and taxes $\left\{\bar{\tau}_{t}\right\}_{t \geq 0}$,

2. or to have an initial wealth $W_{0} / \bar{\tau}_{0}$, an endowment stream $\left\{Y_{t} / \bar{\tau}_{t}\right\}_{t \geq 0}$ and face a sequence of interest rates $\left\{r_{t+1} \frac{\bar{\tau}_{t}}{\bar{\tau}_{t+1}}\right\}_{t \geq 0}$ with zero taxes.

In both cases, the equilibrium sequence of consumption will be the same. If policy instruments are such that $r_{t+1} \frac{\bar{\tau}_{t}}{\bar{\tau}_{t+1}}=r^{*}$, the allocation that solves the semi-open economy problem with non-zero taxes can then be associated to an open economy problem with zero taxes. The following proof derives this result in a more rigorous way.

Proof. First note that the central bank can always set $\left\{\bar{B}_{t+1}, \bar{B}_{t+1}^{*}\right\}_{t \geq 0}$ to target any sequence of domestic interest rates $\left\{r_{t+1}\right\}_{t \geq 0}$ : it just needs to provide loans and deposits at those rates and let agents choose their desired levels of loans and deposits. The corresponding sequence $\left\{\bar{B}_{t+1}, \bar{B}_{t+1}^{*}\right\}_{t \geq 0}$ then follows from equilibrium in the bond market and the central bank's budget constraints.

Denote $p_{t}$ the date- 0 price of a unit of consumption good at date $t$ for households. We normalize $p_{0}=1$. We have $p_{t+1}=\frac{p_{t}}{r_{t+1}}$. 
The equilibrium allocation $\left\{\bar{c}_{t}^{D}, \bar{c}_{t}^{L}\right\}_{t \geq 0}$ is the solution to the following set of equations,

$$
\begin{gathered}
\sum_{t \geq 0}\left[p_{2 t}\left(Y_{2 t}-\bar{\tau}_{2 t} c_{2 t}^{D}\right)+p_{2 t+1}\left(a Y_{2 t+1}-\bar{\tau}_{2 t+1} c_{2 t+1}^{L}\right)\right]-r_{0} L_{0}=0 \\
\sum_{t \geq 0}\left[p_{2 t}\left(a Y_{2 t}-\bar{\tau}_{2 t} c_{2 t}^{L}\right)+p_{2 t+1}\left(Y_{2 t+1}-\bar{\tau}_{2 t+1} c_{2 t+1}^{D}\right)\right]+r_{0} D_{0}=0 \\
\sum_{t \geq 0} \frac{1}{\left(r^{*}\right)^{t}}\left[(1+a) Y_{t}\right]+r^{*} B_{0}^{*}=\sum_{t \geq 0} \frac{1}{\left(r^{*}\right)^{t}}\left(\bar{c}_{t}^{D}+\bar{c}_{t}^{L}\right) \\
\sum_{s=0}^{t}\left[p_{2 s}\left(Y_{2 s}-\bar{\tau}_{2 s} c_{2 s}^{D}\right)+p_{2 s+1}\left(a Y_{2 s+1}-\bar{\tau}_{2 s+1} c_{2 s+1}^{L}\right)\right]-r_{0} L_{0}+p_{2 t+2} \phi Y_{2 t+2} \geq 0 \\
\sum_{s=0}^{t}\left[p_{2 s}\left(a Y_{2 s}-\bar{\tau}_{2 s} c_{2 s}^{L}\right)+\sum_{s=0}^{t-1} p_{2 s+1}\left(Y_{2 s+1}-\bar{\tau}_{2 s+1} c_{2 s+1}^{D}\right)\right]+r_{0} D_{0}+p_{2 t+1} \phi Y_{2 t+1} \geq 0 \\
u^{\prime}\left(c_{t}^{D}\right)=\beta r_{t+1} \frac{\bar{\tau}_{t}}{\bar{\tau}_{t+1}} u^{\prime}\left(c_{t+1}^{L}\right) \\
u^{\prime}\left(c_{t}^{L}\right)=\beta r_{t+1} \frac{\bar{\tau}_{t}}{\bar{\tau}_{t+1}}\left(1+\lambda_{t+1}\right) u^{\prime}\left(c_{t+1}^{D}\right)
\end{gathered}
$$

and the associated slackness conditions. Equations (26) and (27) are the intertemporal budget constraints of both agents, equation (28) the intertemporal resource constraint, and equations (29) and (30) are the borrowing constraints written as of date 0.

The condition on domestic interest rates $r_{t+1}=r^{*} \frac{\bar{\tau}_{t+1}}{\bar{\tau}_{t}}$ implies that $p_{t}=\frac{\bar{\tau}_{0}}{\bar{\tau}_{t}} \frac{1}{\left(r^{*}\right)^{t}}$. The equations defining the equilibrium allocation can then be rewritten

$$
\begin{gathered}
\sum_{t \geq 0}\left[\frac{1}{\left(r^{*}\right)^{2 t}}\left(\frac{Y_{2 t}}{\bar{\tau}_{2 t}}-c_{2 t}^{D}\right)+\frac{1}{\left(r^{*}\right)^{2 t+1}}\left(a \frac{Y_{2 t+1}}{\bar{\tau}_{2 t+1}}-c_{2 t+1}^{L}\right)\right]-r_{0} \frac{L_{0}}{\bar{\tau}_{0}}=0 \\
\sum_{t \geq 0}\left[\frac{1}{\left(r^{*}\right)^{2 t}}\left(a \frac{Y_{2 t}}{\bar{\tau}_{2 t}}-c_{2 t}^{L}\right)+\frac{1}{\left(r^{*}\right)^{2 t+1}}\left(\frac{Y_{2 t+1}}{\bar{\tau}_{2 t+1}}-c_{2 t+1}^{D}\right)\right]+r_{0} \frac{D_{0}}{\bar{\tau}_{0}}=0 \\
\sum_{t \geq 0} \frac{1}{\left(r^{*}\right)^{t}}\left[(1+a) Y_{t}\right]+r^{*} B_{0}^{*}=\sum_{t \geq 0} \frac{1}{\left(r^{*}\right)^{t}}\left(\bar{c}_{t}^{D}+\bar{c}_{t}^{L}\right), \\
\sum_{s=0}^{t}\left[\frac{1}{\left(r^{*}\right)^{2 s}}\left(\frac{Y_{2 s}}{\bar{\tau}_{2 s}}-c_{2 s}^{D}\right)+\frac{1}{\left(r^{*}\right)^{2 s+1}}\left(a \frac{Y_{2 s+1}}{\bar{\tau}_{2 s+1}}-c_{2 s+1}^{L}\right)\right]-r_{0} \frac{L_{0}}{\bar{\tau}_{0}}+\frac{1}{\left(r^{*}\right)^{2 t+1}} \phi \frac{Y_{2 t+2}}{\bar{\tau}_{2 t+2}} \geq 0, \\
\sum_{s=0}^{t}\left[\frac{1}{\left(r^{*}\right)^{2 s}}\left(a \frac{Y_{2 s}}{\bar{\tau}_{2 s}}-c_{2 s}^{L}\right)+\sum_{s=0}^{t-1} \frac{1}{\left(r^{*}\right)^{2 s+1}}\left(\frac{Y_{2 s+1}}{\bar{\tau}_{2 s+1}}-c_{2 s+1}^{D}\right)\right]+r_{0} \frac{D_{0}}{\bar{\tau}_{0}}+\frac{1}{\left(r^{*}\right)^{2 t+1}} \phi \frac{Y_{2 t+1}}{\bar{\tau}_{2 t+1}} \geq 0 \\
u^{\prime}\left(c_{t}^{D}\right)=\beta r^{*} u^{\prime}\left(c_{t+1}^{L}\right), \\
u^{\prime}\left(c_{t}^{L}\right)=\beta r^{*}\left(1+\lambda_{t+1}\right) u^{\prime}\left(c_{t+1}^{D}\right) .
\end{gathered}
$$


Given (25), it is straightforward to see that the allocation $\left\{\bar{c}_{t}^{D}, \bar{c}_{t}^{L}\right\}_{t \geq 0}$ is the decentralized equilibrium associated to the open economy regime, zero taxes, the endowment stream $\left\{\frac{Y_{t}}{\bar{\tau}_{t}}\right\}_{t \geq 0}$, and initial repayments on deposits and loans $r_{0} \frac{D_{0}}{\tau_{0}}$ and $r_{0} \frac{L_{0}}{\tau_{0}}$.

We can now prove Proposition 4.

Proof. Denote $\left\{\bar{c}_{t}^{D}, \bar{c}_{t}^{L}\right\}$ an allocation that satisfies the intertemporal resource constraint, such that consumption is constant for both types of households and $c_{0}^{L}=\rho c_{0}^{D}$. We will now choose the policy instruments to make this allocation the equilibrium allocation of the associated open economy problem.

Denote $\bar{y}=\frac{\sum_{t \geq 0} Y_{t} /\left(r^{*}\right)^{t}}{\sum_{t \geq 0} 1 /\left(r^{*}\right)^{t}}$ the permanent value of the endowment stream, and set $\bar{\tau}_{t}=$ $Y_{t} / \bar{y}$ for $t \geq 3$. Then, the stream of endowments in the associated open economy problem, $Y_{t} / \bar{\tau}_{t}$, is constant and equal to $\bar{y}$ for $t \geq 3$.

Choose $\bar{\tau}_{0}$ sufficiently low so that the following conditions hold:

$$
\begin{gathered}
a \frac{Y_{0}}{\bar{\tau}_{0}}-\bar{c}_{0}^{L}+r_{0} \frac{D_{0}}{\bar{\tau}_{0}} \geq 0 \\
\frac{Y_{0}}{\bar{\tau}_{0}}-\bar{c}_{0}^{D}-\frac{\bar{c}_{1}^{L}}{r^{*}}-r_{0} \frac{L_{0}}{\bar{\tau}_{0}} \geq 0 \\
a \frac{Y_{0}}{\bar{\tau}_{0}}-\bar{c}_{0}^{L}-\frac{\bar{c}_{1}^{D}}{r^{*}}-\frac{\bar{c}_{2}^{D}}{\left(r^{*}\right)^{2}}+r_{0} \frac{D_{0}}{\bar{\tau}_{0}}+\frac{1}{\left(r^{*}\right)^{3}} \phi \frac{Y_{3}}{\bar{\tau}_{3}} \geq 0 \\
\frac{Y_{0}}{\bar{\tau}_{0}}+a \frac{1}{\left(r^{*}\right)^{3}} \frac{Y_{3}}{\bar{\tau}_{3}}-\bar{c}_{0}^{D}-\frac{\bar{c}_{1}^{L}}{r^{*}}-\frac{\bar{c}_{2}^{D}}{\left(r^{*}\right)^{2}}-\frac{\bar{c}_{3}^{L}}{\left(r^{*}\right)^{3}}-r_{0} \frac{L_{0}}{\bar{\tau}_{0}}+\frac{1}{\left(r^{*}\right)^{4}} \phi \frac{Y_{4}}{\bar{\tau}_{4}} \geq 0 .
\end{gathered}
$$

This is possible from the assumption that $r_{0} L_{0}<Y_{0}$. Remark that $\bar{\tau}_{0}$ does not depend on $\bar{\tau}_{1}$ and $\bar{\tau}_{2}$ which have not been set, yet. These four inequalities state that the borrowing constraint in the associated open economy problem valued at the candidate allocation $\left\{\bar{c}_{t}^{D}, \bar{c}_{t}^{L}\right\}$ is non-binding for $t \in[0,3]$ even in the extreme case when $Y_{t} / \bar{\tau}_{t}=0$ for $t=2$ and 3. This way, the borrowing constraint will be strictly non-binding for $t \in[0,3]$ whatever the values of $\bar{\tau}_{1}$ and $\bar{\tau}_{2}$ that we can now set.

Set $\bar{\tau}_{1}$ and $\bar{\tau}_{2}$ to satisfy equation $(25)$ and

$$
\sum_{t \geq 0} \frac{1}{\left(r^{*}\right)^{2 t}} \frac{Y_{2 t}}{\bar{\tau}_{2 t}}+\frac{1}{\left(r^{*}\right)^{2 t+1}} a \frac{Y_{2 t+1}}{\bar{\tau}_{2 t+1}}-r_{0} \frac{L_{0}}{\bar{\tau}_{0}}=\frac{1}{1+\rho}\left[\sum_{t \geq 0} \frac{1}{\left(r^{*}\right)^{t}}\left[(1+a) \frac{Y_{t}}{\bar{\tau}_{t}}\right]+r_{0} \frac{D_{0}-L_{0}}{\bar{\tau}_{0}}\right]
$$


This condition states that in the associated open economy problem the ratio of intertemporal wealth of the cash-poor household and the cash-rich household in $t=0$ equals $\rho$.

Finally, suppose the central bank sets $\left\{\bar{B}_{t+1}, \bar{B}_{t+1}^{*}\right\}_{t \geq 0}$ to target the interest rates $r_{t+1}=r^{*} \frac{\bar{\tau}_{t+1}}{\bar{\tau}_{t}}$. This is always possible as the central bank just needs to provide loans and deposits at those rates and let agents choose their desired levels of loans and deposits.

The sequence $\left\{\bar{\tau}_{t}\right\}_{t \geq 0}$ satisfies the assumptions of Lemma 2. We can therefore look for the equilibrium allocation of the associated open economy problem with zero tax. In this associated problem, the endowments are constant and equal to $\bar{y}$ for $t \geq 3$, so the borrowing constraints do not bind for $t \geq 4: \lambda_{t+1}=0, \forall t \geq 4$.

Consider the candidate allocation $\left\{\bar{c}_{t}^{D}, \bar{c}_{t}^{L}\right\}$. It is the equilibrium allocation if the constraint does not bind either for $t \in[0,3]$, which is ensured by conditions (33). Therefore, $\left\{\bar{c}_{t}^{D}, \bar{c}_{t}^{L}\right\}$ is also an equilibrium allocation of the original problem. By definition, it is such that consumptions are constant for each type of households and the ratio of consumptions is equal $c_{0}^{L} / c_{0}^{D}=\rho$. Since consumption is constant for both households, it has to be that the borrowing constraints never bind. 


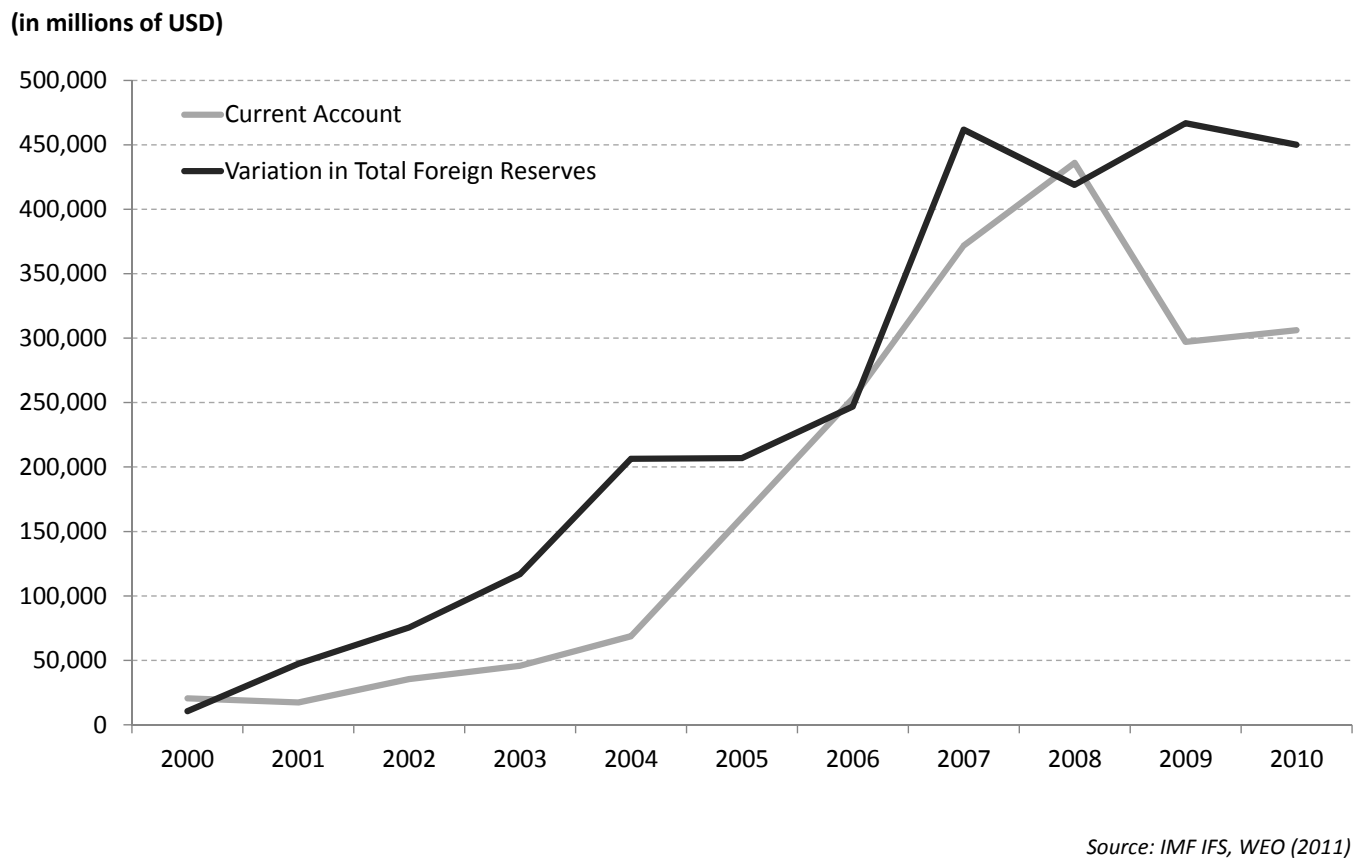

Figure 1: Evolution of Chinese Current Account and Foreign Reserves Accumulation 
(in billions of Yuan)

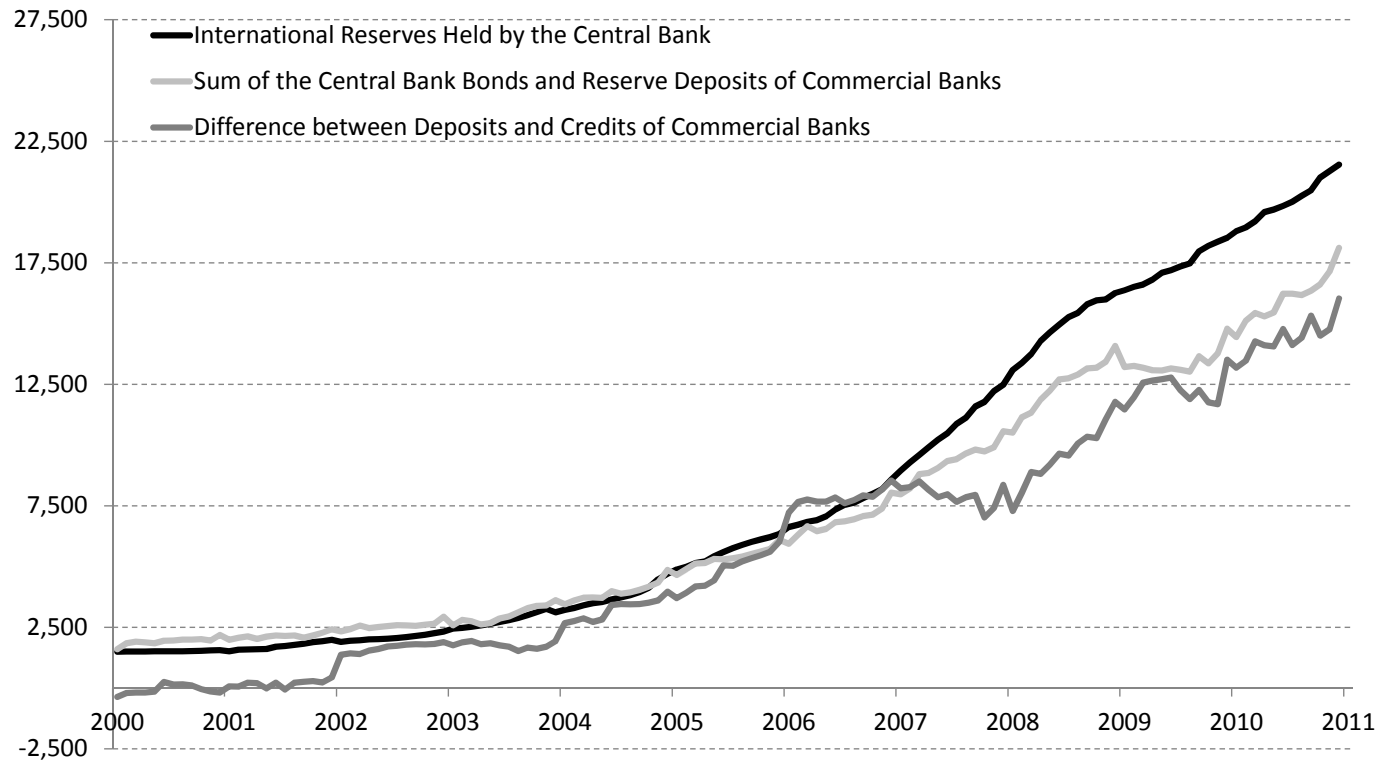

Source: IMF IFS database

Figure 2: Saving Instruments of the Central Bank and the Excess of Deposits over Lending 


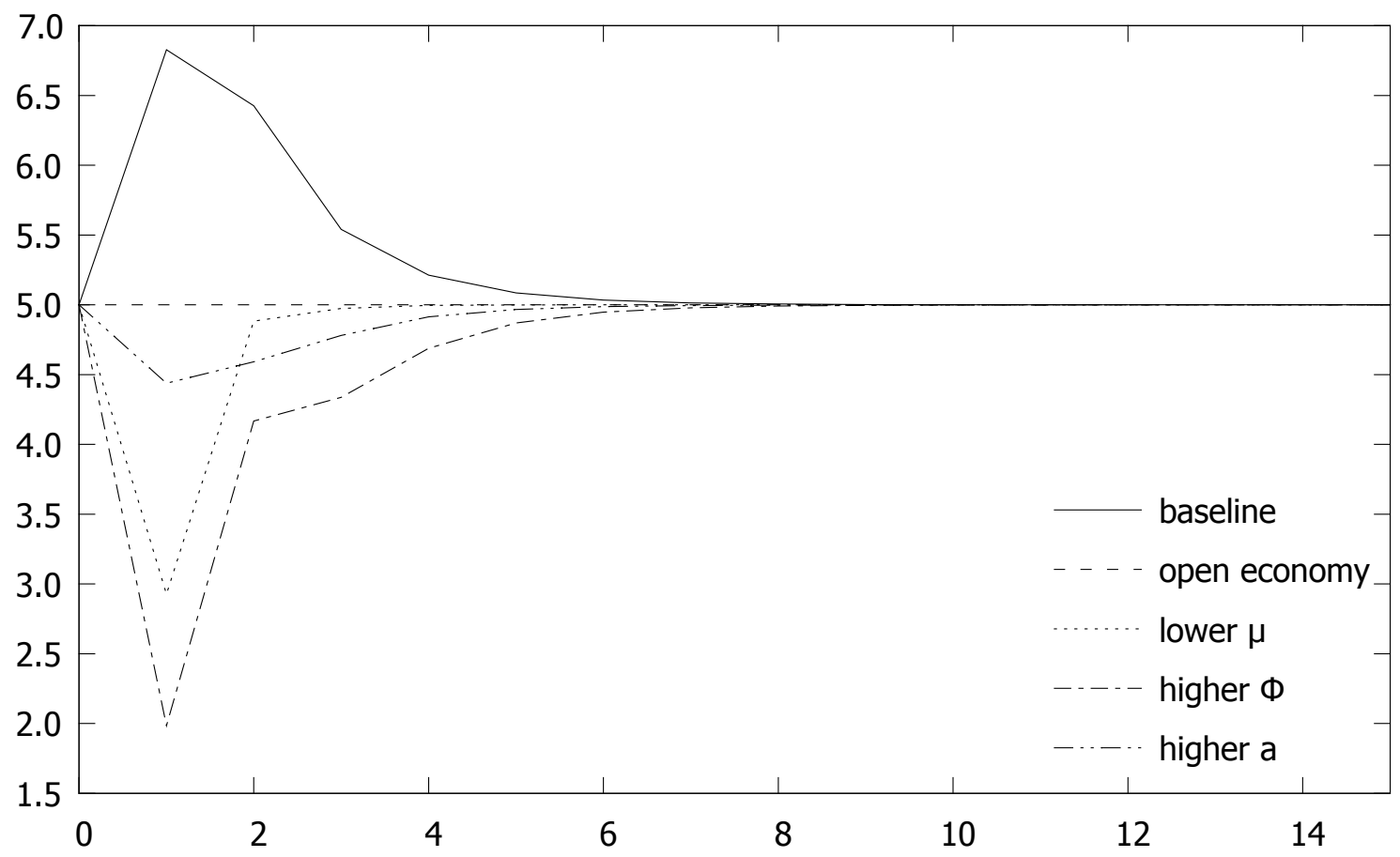

Figure 3: Optimal interest rate $r-1$, in percentage points. 

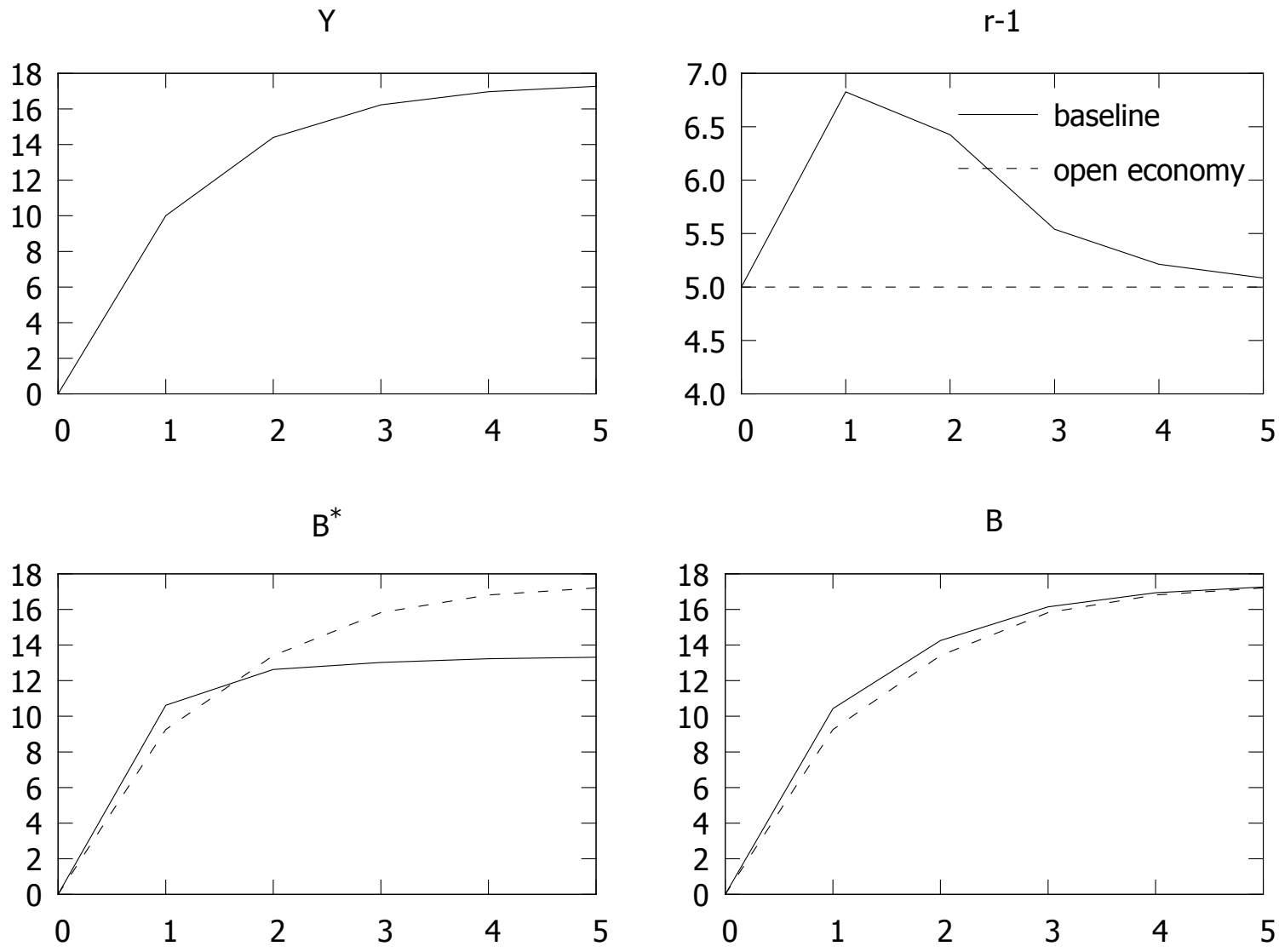

$\mathrm{D}$
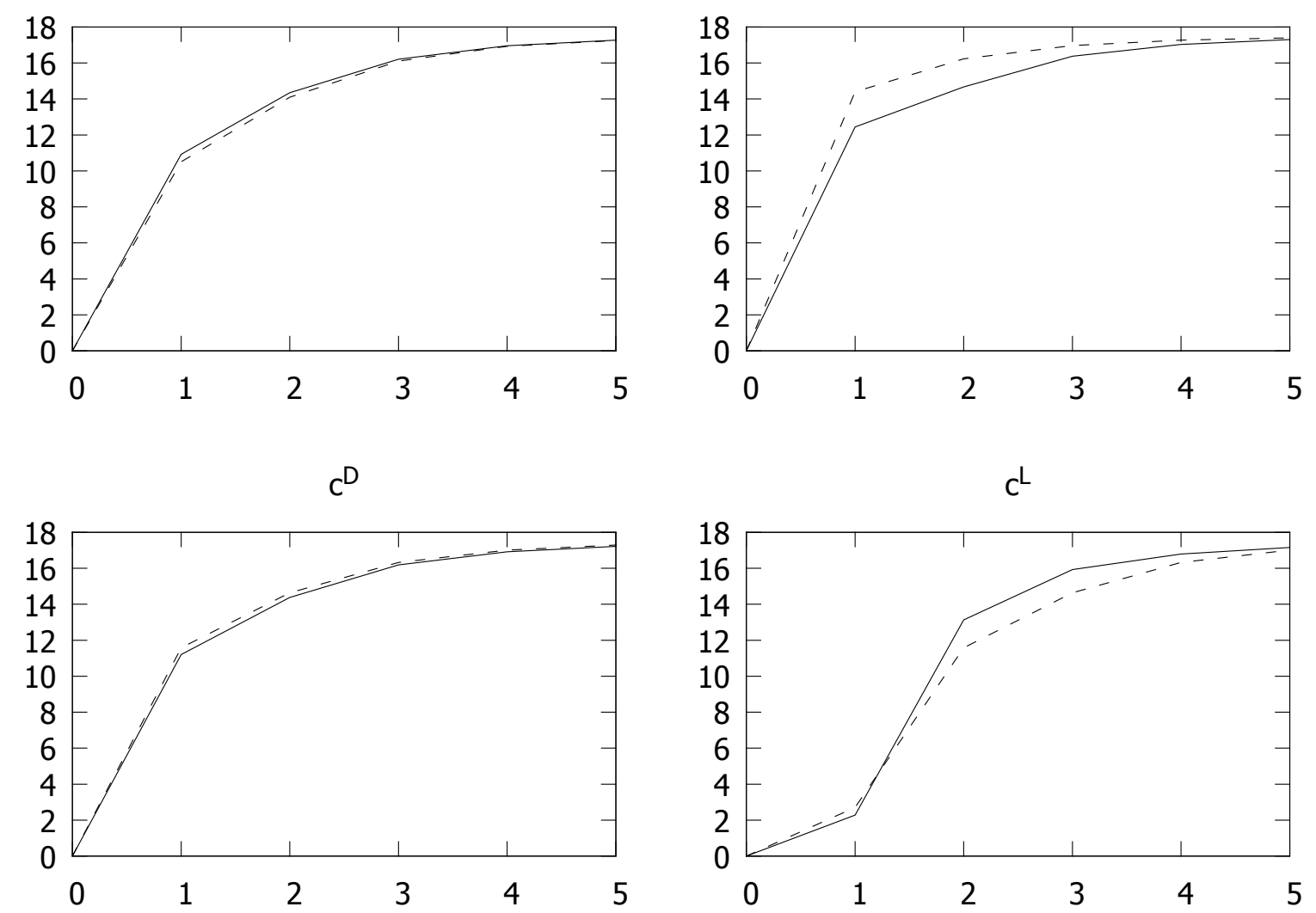

Figure 4: High optimal domestic interest rate. All variables are displayed as percentage changes from their initial value. The interest rate $r-1$ is in percentage points. 

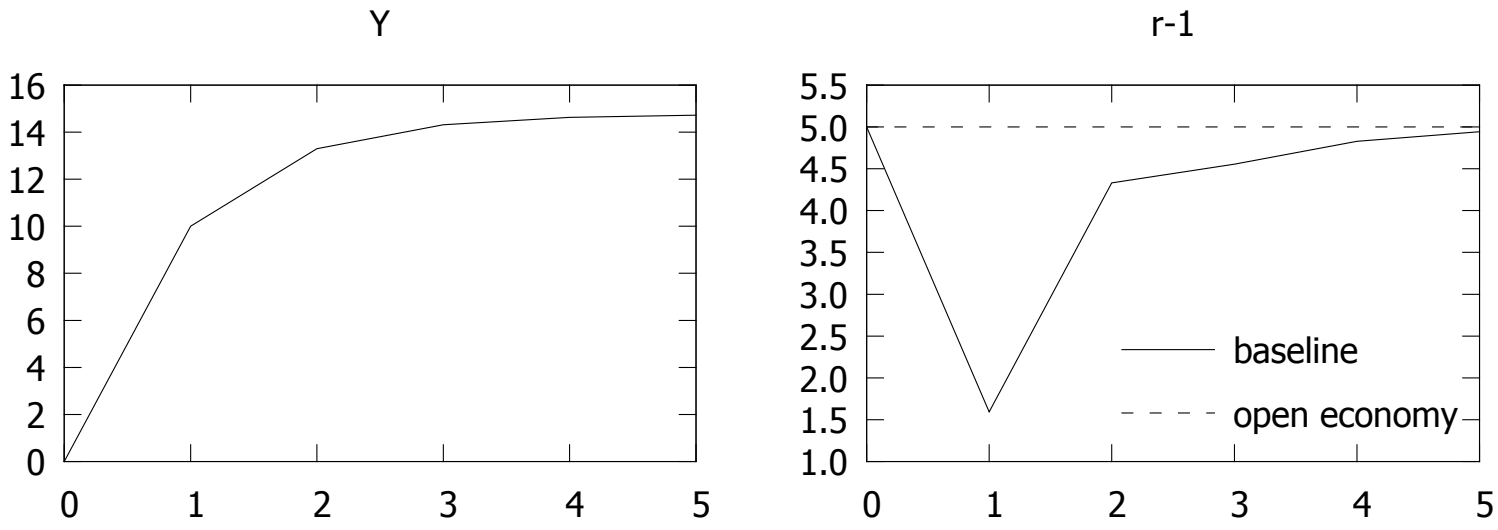

$\mathrm{B}^{*}$

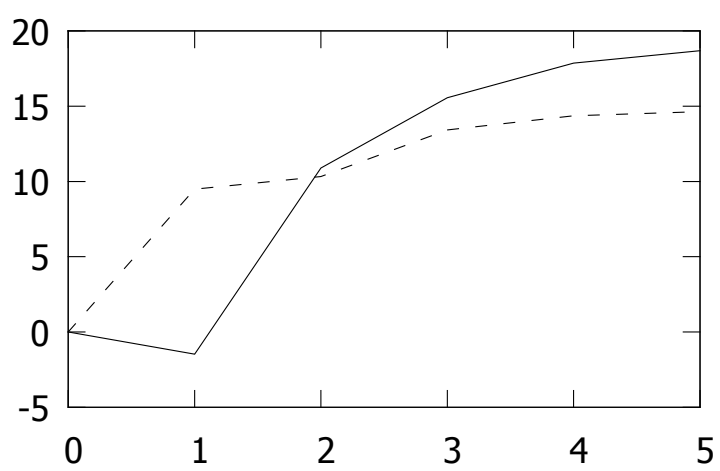

B

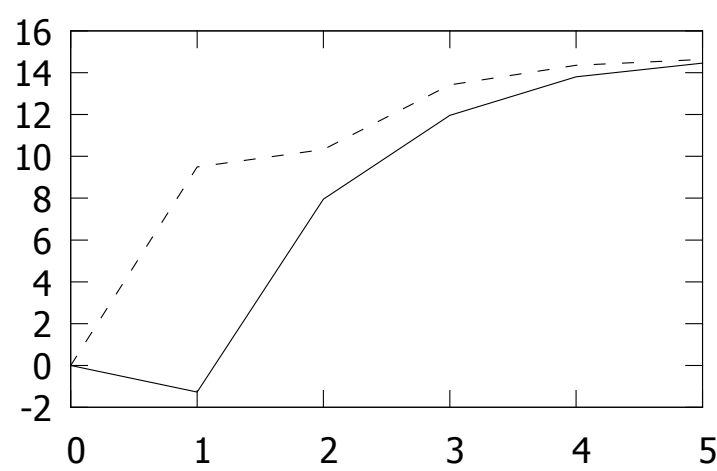

$\mathrm{D}$
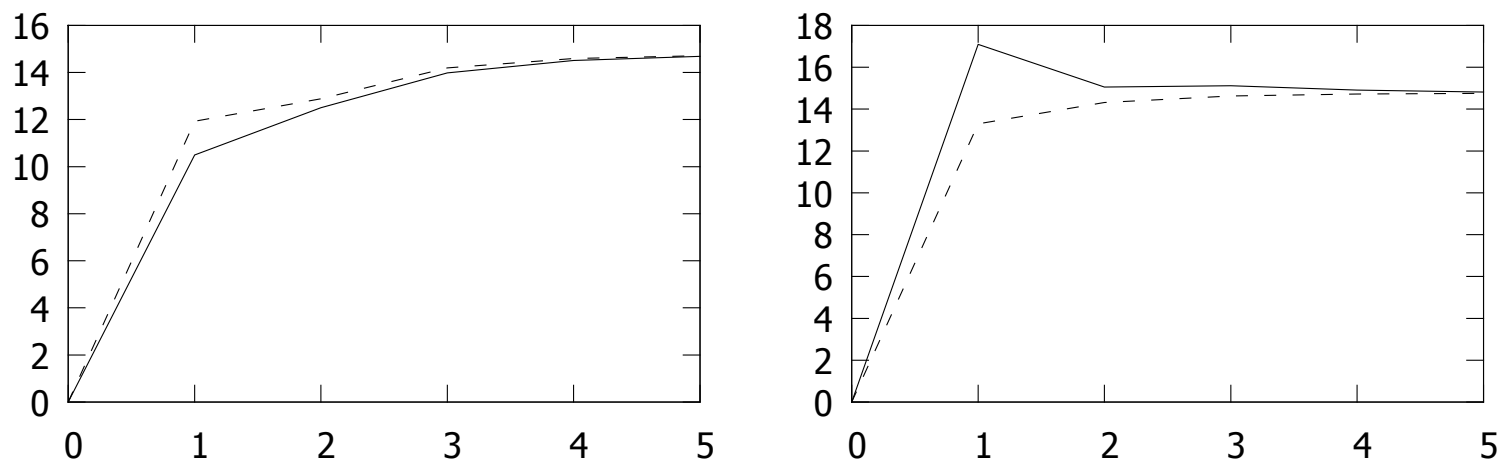

$C^{\mathrm{D}}$

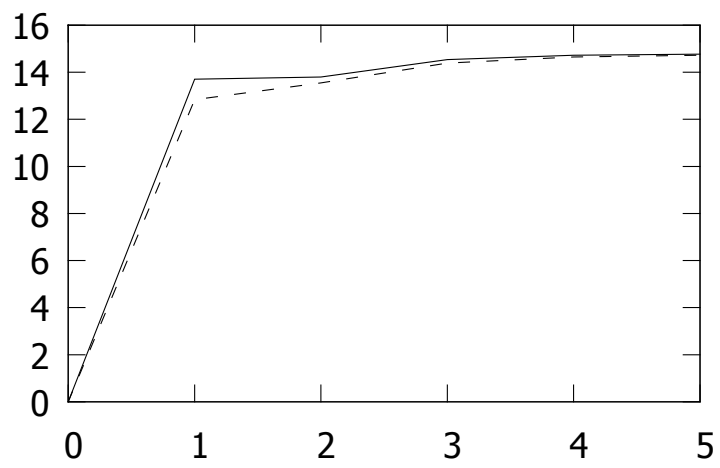

$c^{L}$

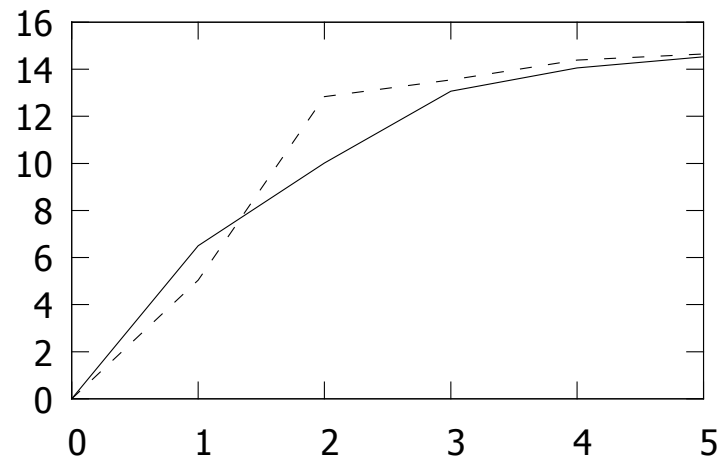

Figure 5: Low optimal domestic interest rate. All variables are displayed as percentage changes from their initial value. The interest rate $r-1$ is in percentage points. 
Y

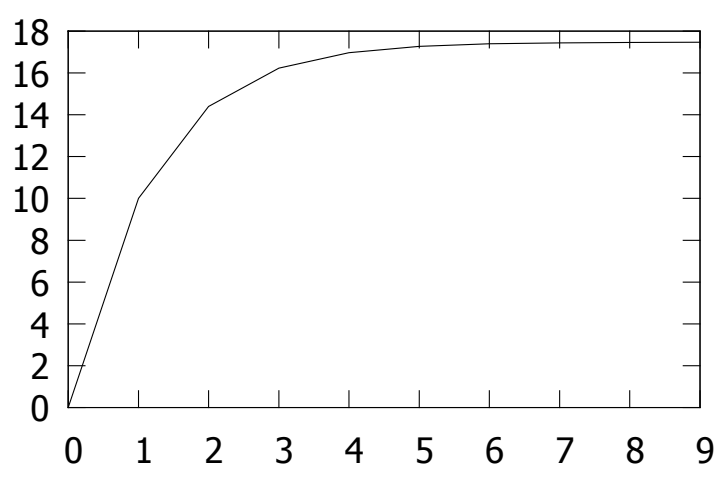

$B^{*}$

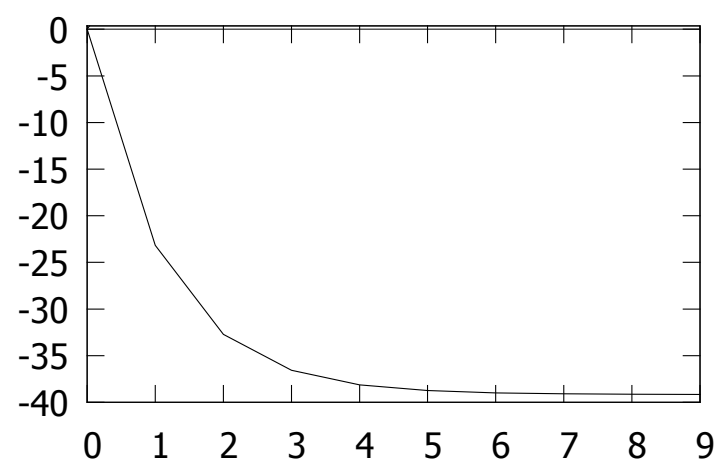

$\mathrm{D}$

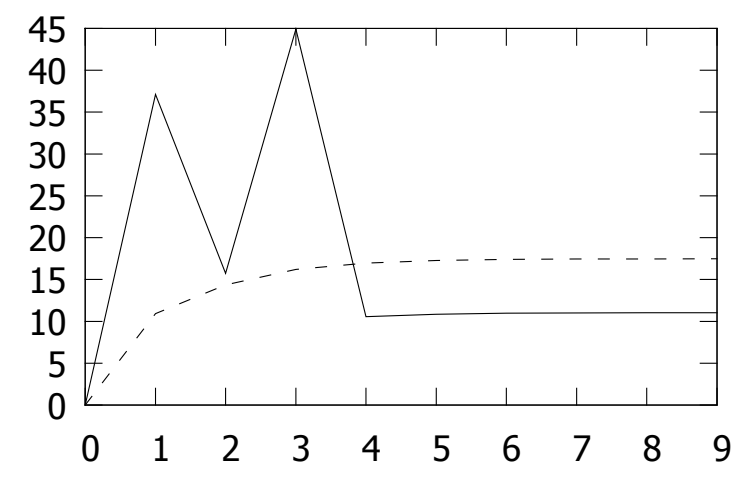

$c^{D}$ and $c^{L}$

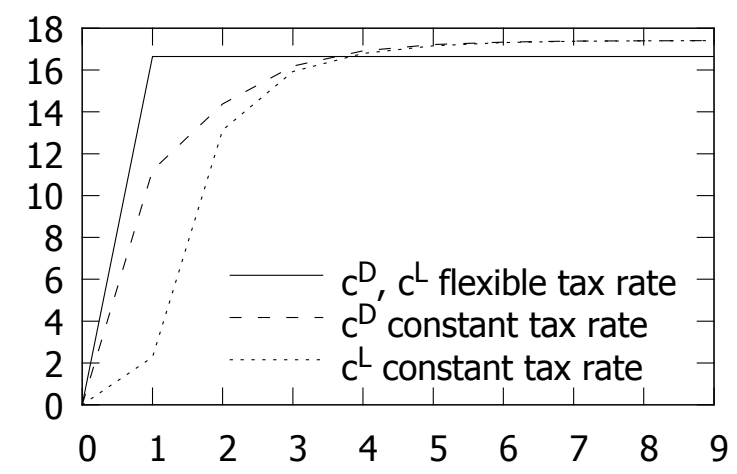

r-1

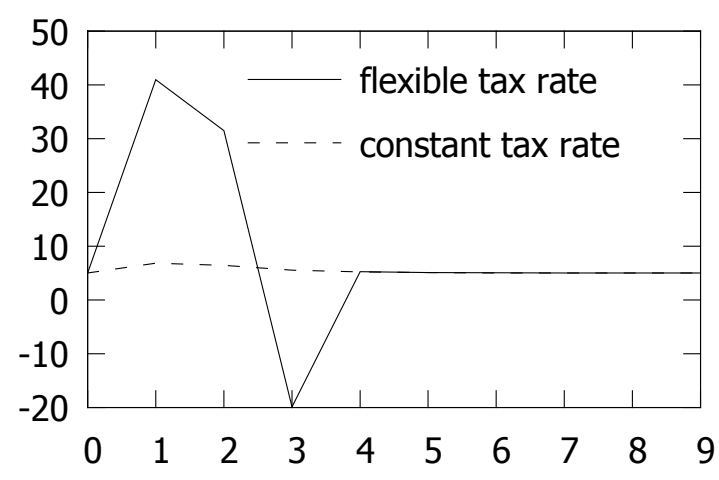

B

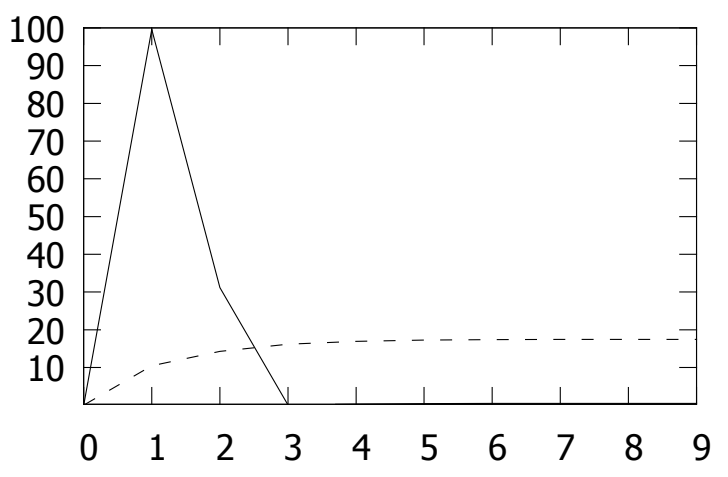

$\mathrm{L}$

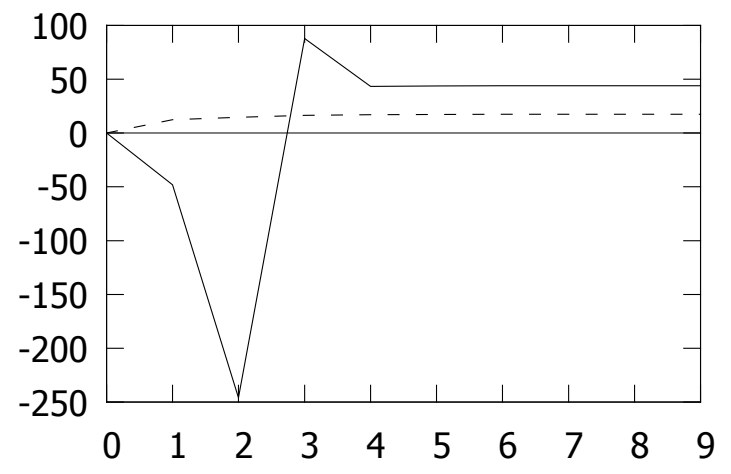

tax rate $\mathrm{T}-1$

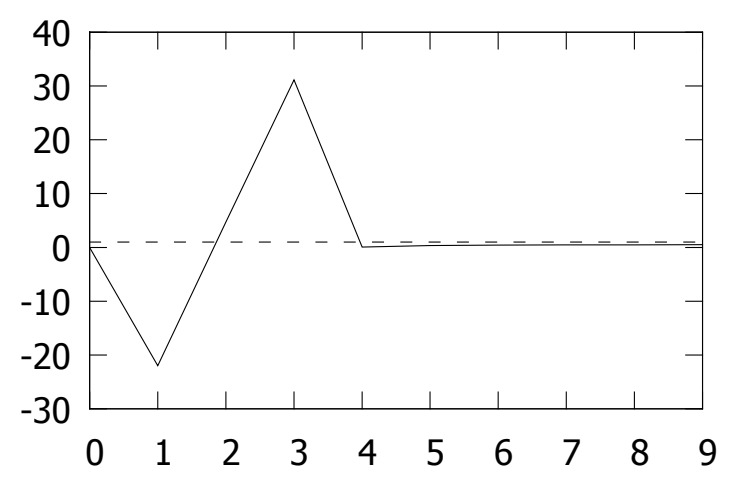

Figure 6: Optimal policy with flexible tax rates. All variables are displayed as percentage changes from their initial value. The interest rate $r-1$ and the tax rate $\tau-1$ are in percentage points. 